\title{
Rapid Detection and Recognition of Organic Pollutants at Trace Levels by Surface-Enhanced Raman Scattering
}

\author{
Zhengjun Zhang, Qin Zhou and Xian Zhang \\ Tsinghua University \\ P. R. China
}

\section{Introduction}

Organic pollutants are harmful even at trace level in the environment, and they are difficult to detect at that concentration. Our work provides a rapid and sensitive method - surface-enhanced Raman scattering - to detect and distinguish isomers of organic pollutants.

\section{Application of surface-enhanced Raman scattering to organic pollutant detection}

In the modern world, environmental problems have attracted more and more attention, for environmental pollutants are extremely harmful to human beings' health. Environmental pollutants, such as persistent organic pollutants, are widely separated in the environment and difficult to detect at trace level.

Within persistent organic pollutants, polychlorinated biphenyls (PCBs), due to their excellent dielectric properties, had been widely used since the 1920s in transformers, heat transfers, capacitors, etc., and had polluted nearly everywhere in the world.[1] In recent years, however, they have been found to be very harmful to human beings. They may cause serious diseases, such as cancers and gene distortion, when exceeding the critical dose in human bodies, and more seriously, PCBs can be accumulated in plants and animals from the environment and yield higher doses in human bodies, making PCBs very dangerous to human beings even in trace amounts.[1-3] Therefore, the detection of PCBs in trace amounts is crucial. Currently, the mostly applied detection technique for PCBs is the combination of high-resolution gas chromatography and mass spectrometry. It requires, however, very sophisticated devices, standard samples, complicated pretreatments of samples, favourable experimental environments and experienced operators.[4-7] Thus, new methods are demanded especially for the rapid detection of trace amounts of PCBs.

Surface-enhanced Raman scattering (SERS) has been proven to be an effective way to detect some organics. ${ }^{[8]}$ With the great progress of nanoscale technology in recent years, SERS has attracted enormous attention due to its excellent performance and potential applications in the detection of molecules in trace amounts, even single molecule detection. For instance, using Ag nanorods as SERS substrates Rhodamine 6G with concentration of 
$10^{-14} \mathrm{M}$ (dissolved in water) was detected;[9] with the alumina-modified AgFON substrates, bacillus subtilis spores were detected to $10^{-14} \mathrm{M} ;[10,11]$ Vo-Dinh reported even the detection of specific nucleic acid sequences by the SERS technique.[12-14] In spite of the numerous studies on the application as a chemical and biological sensor,[15-17] the SERS technique has not yet been employed to detect PCBs as they are hardly dissolved in water.

While lots of researchers investigate SERS in the detection of biological and medical molecules, ${ }^{[12-17]}$ SERS has also proved an excellent method in environment pollutants' detection, such as trace amounts of polychlorinated biphenyls (PCBs). ${ }^{[45,47]}$

\section{Fingerprint character of SERS: Understanding and simulating Raman spectrum of organic pollutants}

SERS is an excellent method to detect and recognize trace amounts of organic pollutants as organic pollutants have different Raman spectrums due to their different molecule vibration modes, even when they have similar physical and chemical properties. These different Raman spectrums have peaks with different Raman shifts and different peak heights. These peaks are sharp and unique, which show a fingerprint character of SERS spectra and make SERS spectra easily distinguishable from each other.

The Raman spectrum shows detailed structure information of organic pollutants. Therefore, one can detect and recognize organic pollutants via the SERS spectrum even at trace level, just like one can recognize crystal structures via X-ray diffraction.

The relationship between Raman spectrum and molecule vibration modes can be analyzed by density functional theory. We performed a simulation using the Gaussian 03 programme package with the density functional theory. The simulations were carried out with the Becke's three-parameter hybrid method using the Lee-yang-Parr correlation functional (B3LYP) and the LANL2DZ basis set.[46] The Gaussian View was used to input investigated compounds data visually.

\section{Fabrication high sensitive silver nanorods SERS substrates}

The detection sensitivity of SERS depends considerably on the surface property of the SERS substrate. High aspect ratio, nanostructured $\mathrm{Ag}, \mathrm{Au}, \mathrm{Cu}$ substrates are proved to be good SERS substrates. For instance, using ordered arrays of gold particles prepared through a porous alumina template as the SERS substrate, Rhodamine 6G (R6G) molecules were detected to a concentration limit of $10^{-12} \mathrm{M}$; arrays of silicon nanorods coated with thin films of Ag served as good SERS substrates for R6G molecule detection, etc. ${ }^{[12,16]}$ Thus the preparation of SERS substrates with preferred surface property is of great importance. There are several methods to prepare these kinds of SERS substrates and in this chapter we take glancing angle deposition as an example.

Glancing angle deposition (GLAD) technique is a simple but powerful means of producing thin films with pre-designed nanostructures, such as nanopillars, slanted posts, zigzag columns and spirals. Silver nanorod arrays prepared by GLAD are excellent SERS substrates.

In addition, the SERS properties are related to the optical properties of the nanorod arrays. Both SERS properties and optical properties depend on the structure of the nanorods, such as the shape, length, separation, tilting angle and so on, which can be tuned by the deposition conditions. 


\subsection{Fabrication of sensitive SERS substrates by GLAD}

The detection sensitivity of the SERS technique depends greatly on the surface property of the SERS substrate.[40, 41] Among the approaches so far available to prepare nanostructured materials, the glancing angle deposition (GLAD) technique is a simple but powerful means of producing thin films with pre-designed nanostructures, ${ }^{[42,43]}$ such as nanopillars, slanted posts, zigzag columns, spirals,[18] [19] etc. [20-23] For example, arrays of Ag nanorods were found to be good SERS substrates for the detection of trans-1,2bis(4-pyridyl)ethane molecules, with a SERS enhancement factor greater than $10^{8} .{ }^{[16]}$ It is therefore of great interest to investigate the growth of metal nanostructures by the GLAD technique.[44]

Pristine Si wafers with (001) orientation were used as substrates. These were supersonically cleaned in acetone, ethanol and de-ionized water baths in sequence, and were fixed on the GLAD substrate in an e-beam deposition system. The system was pumped down to a vacuum level of $3 \times 10^{-5} \mathrm{~Pa}$ and then the thin $\mathrm{Ag}$ film was deposited on the substrate with a depositing rate of $0.5 \mathrm{~nm} / \mathrm{s}$, with the thickness monitored by a quartz crystal microbalance. To produce films of aligned Ag nanorods, the incident beam of Ag flux was set at $\sim 85$ o from the normal of the silicon substrate, at different substrate temperatures. The morphology and structure of the thin Ag films was characterized by scanning electron microscope (SEM), transmission electron microscope (TEM) and high-resolution TEM, selected area diffraction (SAD) and X-ray diffraction (XRD), respectively. The performance of the nanostructured Ag films as SERS substrates was evaluated with a micro-Raman spectrometer using R6G as the model molecule.

It is well known that the major factors influencing the growth morphology of the films by GLAD are the incident direction of the depositing beam flux, the temperature and the movement of the substrate, and the deposition rate, etc. When fixing the incident Ag flux at $\sim 85$ o from the normal of the substrate and the deposition rate at $\sim 0.5 \mathrm{~nm} / \mathrm{s}$, the growth morphology of the Ag films was greatly dependent on the temperature and movement of the substrate. Figure 1 shows the growth morphology of thin Ag films versus the temperature and movement of the substrate. The SEM micrographs were taken by a FEI SEM (QUANTA 200FEG) working at $20 \mathrm{kV}$.

Figure 1(a) and (b) shows typical SEM images of the surface morphology of thin Ag films deposited at $120{ }^{\circ} \mathrm{C}$, without substrate rotation and with substrate rotation at a speed of $0.2 \mathrm{rpm}$, respectively. One sees from the images that at this temperature, $\mathrm{Ag}$ nanorods formed in two films with a length of $500 \mathrm{~nm}$, yet they were not well separated - most nanorods were joined together. A major difference between the two is the growth direction of the joined nanorods, i.e. without rotation the nanorods grew at a glancing angle on the substrate, while with substrate rotation the nanorods grew vertically aligned. Another difference noticeable is the size of the nanorods, i.e. nanorods grown with substrate rotation have a slightly larger diameter.

Figure 1(c) and (d) shows respectively the surface morphology of thin Ag films deposited at $-40{ }^{\circ} \mathrm{C}$, without substrate rotation and with rotation at a speed of $0.2 \mathrm{rpm}$. Comparing with figures $1(\mathrm{a})$ and (b), it can be seen that the decrease in the deposition temperature led to the separation of Ag nanorods in the two films, while the rotation of the substrate also determined the growth direction and diameter of the nanorods, as observed from figures 1(a) and 1(b). The Ag nanorods grown at this temperature are 20$30 \mathrm{~nm}$ in diameter, $\sim 800 \mathrm{~nm}$ in length and are well separated. Therefore, through adjusting the temperature and movement of the substrate one can grow well separated and aligned Ag nanorods on planar silicon substrates. 


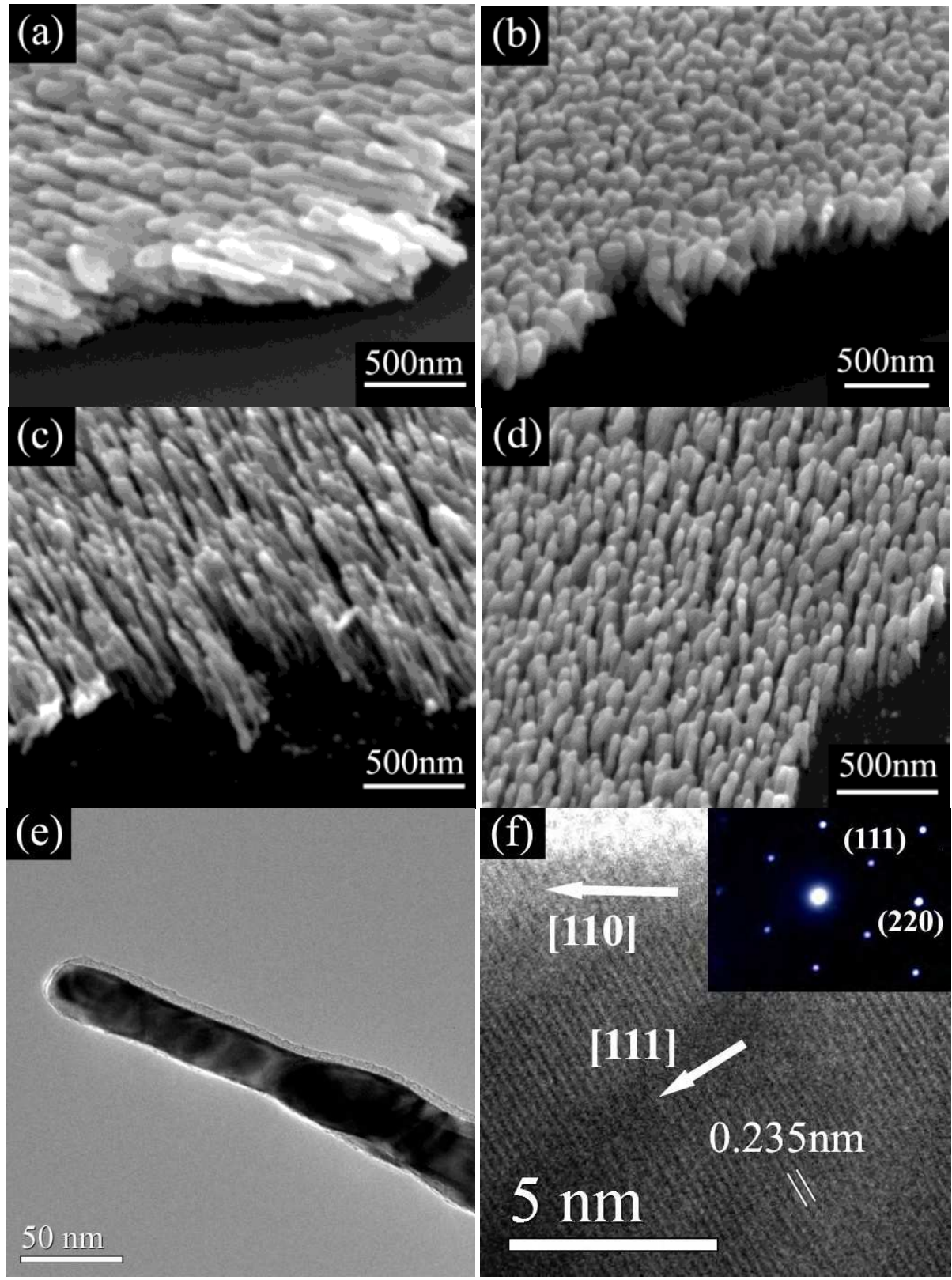

Fig. 1. Growth morphology of thin Ag films by GLAD at various conditions. (a) at $120^{\circ} \mathrm{C}$ without substrate rotation; (b) at $120^{\circ} \mathrm{C}$ and substrate rotation at $0.2 \mathrm{rpm}$; (c) at $-40{ }^{\circ} \mathrm{C}$ without substrate rotation; and (d) at $-40 \circ \mathrm{C}$ and substrate rotation at $0.2 \mathrm{rpm}$. (e) and (f) shows respectively a bright-field TEM and a HRTEM image of the nanorods shown by figure 1(c); inset of (f) is the corresponding SAD pattern. 
Figure 1(e) and 1(f) shows respectively a bright-field TEM and a HRTEM image of Ag nanorods shown by figure 1(c); inset of figure 1(f) is the corresponding SAD pattern. The images and the SAD pattern were taken with a JEM-2011F working at $200 \mathrm{kV}$. One sees from the figures that the Ag nanorod is $\sim 30 \mathrm{~nm}$ in diameter and its micro-structure is single crystalline. By indexing the SAD pattern it is noticed that during the growth process the $\{111\}$ plane of the nanorod was parallel to the substrate surface, with its axis along the $<110>$ direction. This was confirmed by XRD analysis. Figure 2 shows a XRD pattern of the Ag nanorods shown by figure 1(c). The pattern was taken with a Rigaku X-ray diffractometer using the $\mathrm{Cu} \mathrm{k}_{\square}$ line, working at the $\theta-2 \theta$ coupled scan mode. From the figure, a very strong (111) texture is observed, indicating that the $\{111\}$ plane of the Ag nanorods was parallel to the substrate surface. These suggest that one can produce arrays of aligned, single crystalline Ag nanorods by the GLAD technique even at a low substrate temperature, i.e. $-40{ }^{\circ} \mathrm{C}$.

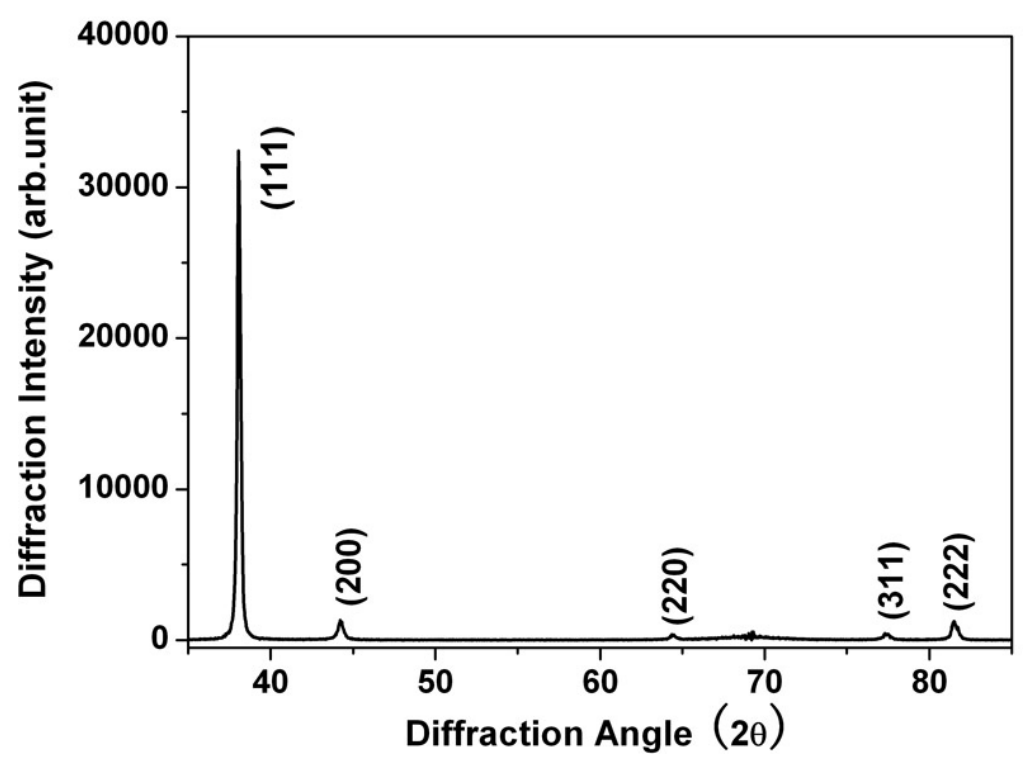

Fig. 2. A XRD pattern of the Ag film consisting of well separated, single crystalline nanorods shown by figure 1 (c).

By using Rhodamine 6G as the model molecule, the performance of thin Ag films shown by figures $1(\mathrm{a})-(\mathrm{d})$ is examined as the SERS substrates. These samples were dipped in a $1 \times 10^{-6} \mathrm{~mol} / \mathrm{L}$ solution of R6G in water for 30 minutes and dried with a continuous gentle nitrogen blow. Figure 3(a) and 3(b) show Raman spectra of R6G obtained on the four nanostructured Ag films by a Reinshaw 100 Raman spectrometer using a $514 \mathrm{~nm} \mathrm{Ar}^{+}$laser as the excitation source. It is observed that with the thin Ag films as the SERS substrate, all spectra exhibit clearly the characteristic peaks of R6G molecules, at 612, 774, 1180, 1311, 1361, 1511, 1575 and $1648 \mathrm{~cm}^{-1}$, respectively.[12] However, the intensity of the Raman peaks was dependent on the morphology of the films. It is noticed that on Ag films consisting of well separated nanorods, see figures 3(b), the Raman peaks of R6G are much stronger than those on films of joined nanorods, see figures 3(a). This suggests that arrays of aligned but well separated Ag nanorods represent excellent SERS performance. 

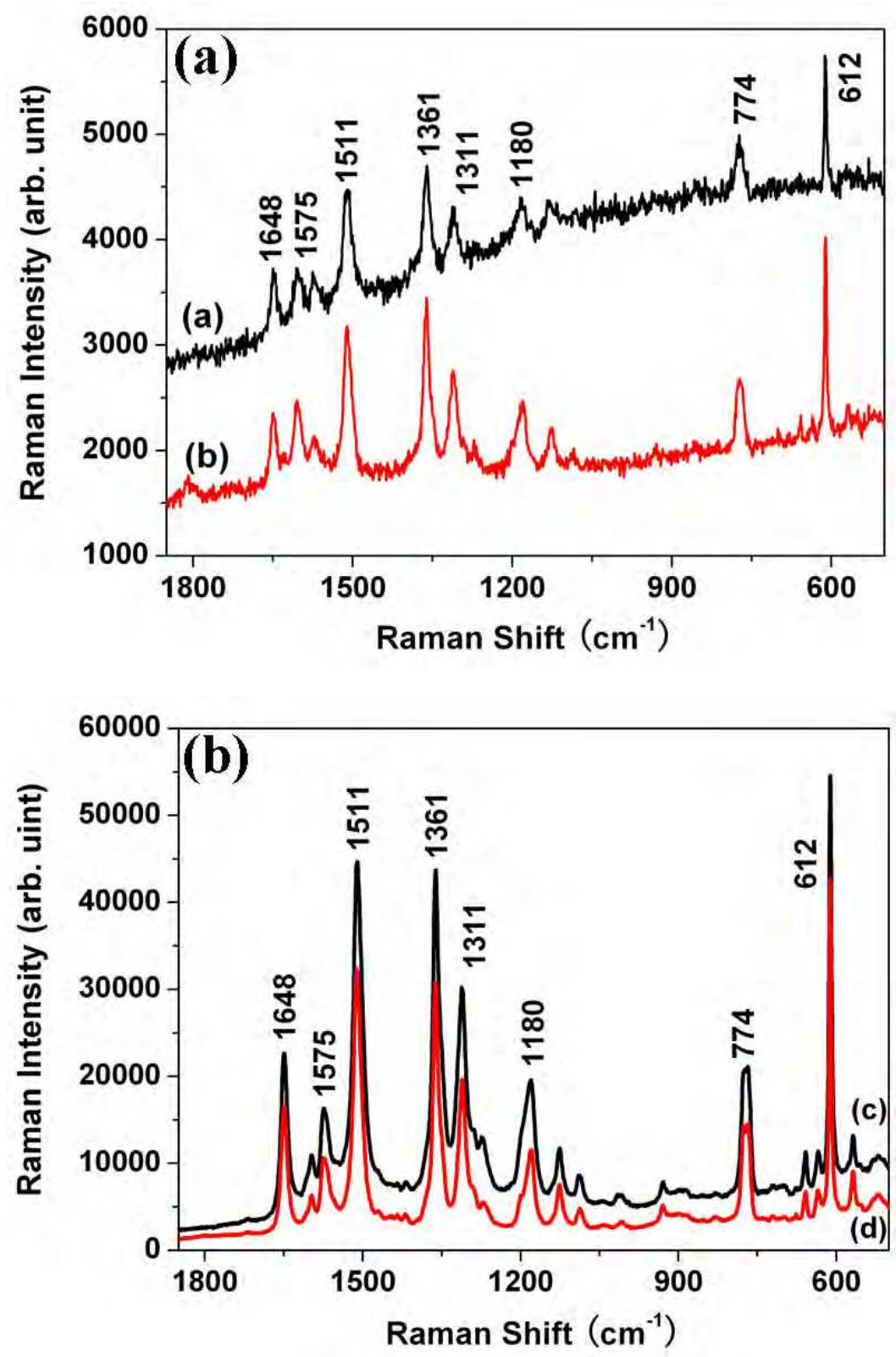

Fig. 3. Raman spectra of R6G on thin Ag films consisting of (a) joined nanorods shown by figures 1(a) (black line) and 1(b) (grey line); and (b) separated Ag nanorods shown by figures 1(c) (black line) and 1(d) (grey line), respectively, at a concentration of $1 \times 10^{-6} \mathrm{~mol} / \mathrm{L}$. 

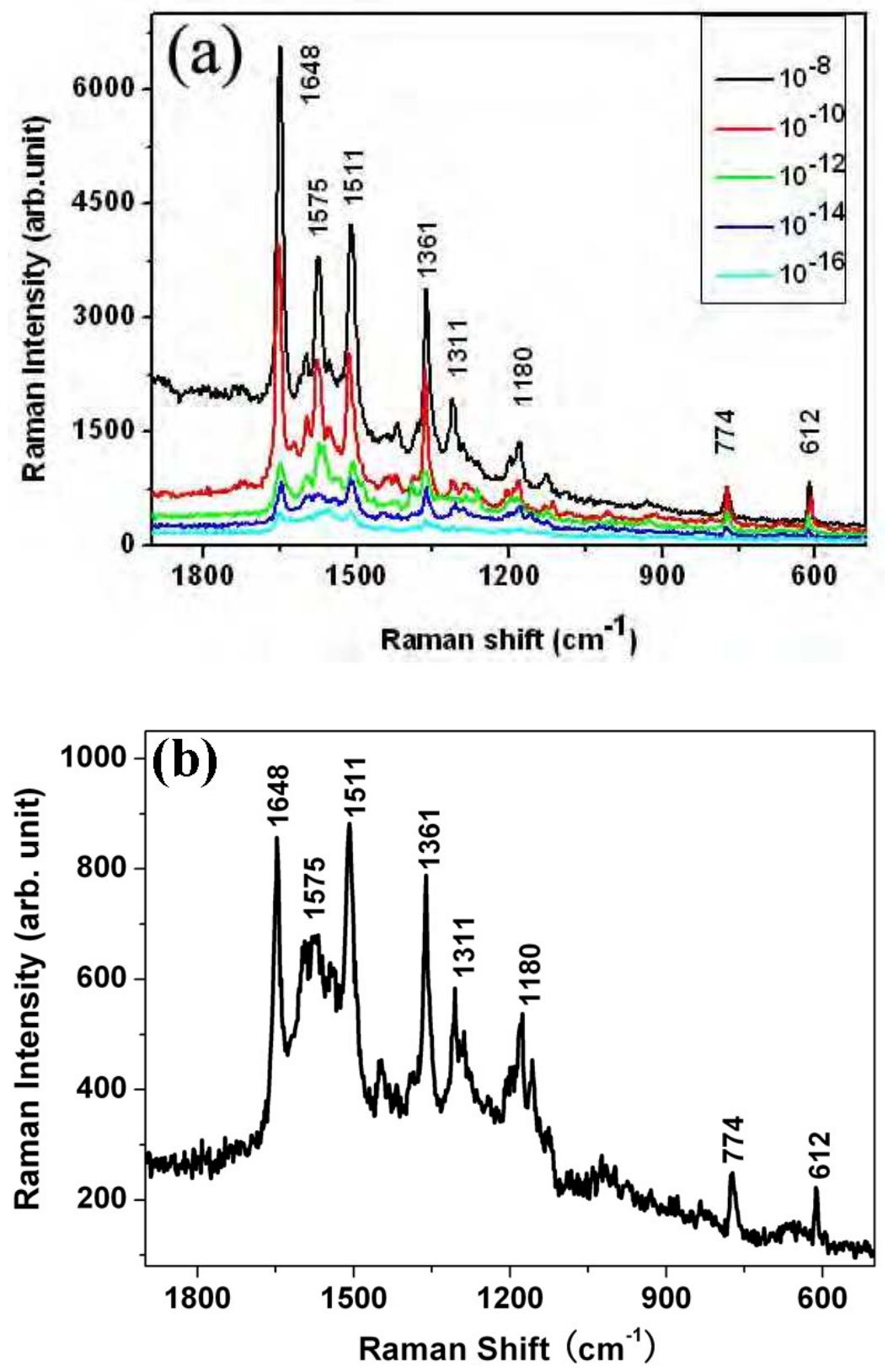

Fig. 4. (a) Raman spectra of R6G at concentrations ranging from $1 \times 10^{-8}$ to $1 \times 10^{-16} \mathrm{~mol} / \mathrm{L}$; and (b) the Raman spectrum of R6G at a concentration of $1 \times 10^{-14} \mathrm{~mol} / \mathrm{L}$, on the thin $\mathrm{Ag}$ film consisting of well separated, single crystalline Ag nanorods. 
Using arrays of aligned Ag nanorods shown by figures 1(c) and 1(d) as SERS substrates, we examined the detection limit of R6G molecules in water by the SERS technique. Figure 4(a) shows Raman spectra of R6G obtained on Ag nanorods shown by figure 1(c), as a function of the concentration of R6G in water ranging from $1 \times 10^{-8}$ to $1 \times 10^{-16} \mathrm{~mol} / \mathrm{L}$. Similar results were also obtained for Ag nanorods shown by figure 1(d). The Raman spectra were obtained by one scan with an accumulation time of $10 \mathrm{~s}$, at a laser power of $1 \%$ to avoid decomposition of R6G. It is found that characteristic peaks of R6G were all observed at all concentrations. To clearly show this, we plot the Raman spectrum at 10-14 $\mathrm{mol} / \mathrm{L}$ in figure $4(\mathrm{~b})$. It is noticed that although the intensity of the peaks is almost two orders lower than that at $10^{-6} \mathrm{~mol} / \mathrm{L}$, the spectrum contains the clear characteristic peaks of R6G.[12] These suggest that Ag films consisting of aligned and well separated Ag nanorods with single crystalline could serve as excellent SERS substrate for trace amount detection of R6G molecules. However, in the Raman spectrum at 10-16 mol/L in figure 4(a), some of the peaks of R6G disappear. That suggests the concentration limit of this method is $10^{-14} \mathrm{~mol} / \mathrm{L}$ in the authors' work.[9]

\subsection{Enhancing the sensitivity of SERS substrates via underlayer films}

Although the Ag nanorod arrays present sensitive SERS performance, it is still necessary to enable the substrate to detect organic pollutants at trace amount with adequate sensitivity. There are several ways to promote the sensitivity of Ag nanorods as SERS substrates.

Much effort has been devoted to achieving highly sensitive SERS substrates. In particular, multilayer structures can improve SERS enhancement, such as "sandwich" structures with silver oxide or carbon inside and $\mathrm{Ag}$ or $\mathrm{Au}$ as both underlayer and overlayer.[24-28] Other researchers found that multilayer structures of $\mathrm{Ag} / \mathrm{Au}$ nanostructures on the smooth metallic underlayer exhibited better SERS sensitivity compared to those without metallic underlayer $\left(\mathrm{EF}=5 \times 10^{8}\right)$. [29-31] However, the factor that governs the enhancement for multilayer structures is not very clear. Recently, Misra et al. obtained remarkably high SERS sensitivity using a micro-cavity with a radius of several micrometers. [32] Shoute et al. obtained high SERS signals $\left(\mathrm{EF}=6 \times 10^{6}\right)$ for molecules adsorbed on the silver island films supported by thermally oxidized silicon wafers and declared that the additional enhancement was due to the optical interference effect.[33] All the above experiments and those conducted by Driskell et al. suggested that the underlayer reflectivity could play an important role in the multilayer SERS substrates.[29]

We have investigated in detail the relationship of underlayer reflectivity and the SERS enhancement of Ag nanorod substrates prepared by oblique angle deposition. We use thin films of different materials with different thicknesses as underlayers to modulate the reflectivity systematically. With the coating of the same Ag nanorods, we find that the SERS intensity increases linearly with the underlayer reflectivity. This conclusion can be explained by a modified Greenler's model we recently developed.[34]

To change the reflectivity of the underlayer films, one can vary the dielectric constant and the thickness of the films systematically. We proposed to use $\mathrm{Ag}, \mathrm{Al}, \mathrm{Si}$ and $\mathrm{Ti}$ films, since they have different dielectric constants and can be fabricated easily. With a transfer matrix method, we can calculate the reflectivity of those films.[35, 36] Figure 5(a) shows the calculated reflectivity spectra of $100 \mathrm{~nm} \mathrm{Ag}, \mathrm{Al}, \mathrm{Si}$, and Ti films. In general, the reflectivity, $R_{\mathrm{Ag}}>R_{\mathrm{Al}}>R_{\mathrm{Ti}}>R_{\mathrm{Si}}$, except that at $\lambda \sim 600 \mathrm{~nm}$ where the Si film has a large constructive interference. Figure 5(b) plots the film thickness dependent reflectivity for $\mathrm{Ag}, \mathrm{Al}, \mathrm{Si}$ and $\mathrm{Ti}$ at a fixed wavelength $\lambda_{0}=785 \mathrm{~nm}$. The reflectivity of $\mathrm{Ag}, \mathrm{Al}, \mathrm{Ti}$, e.g. metals, increases 
monotonically with the film thickness $d$. The reflectivity $R$ of $\mathrm{Ag}, \mathrm{Al}$ and $\mathrm{Ti}$ thin films increases sharply when $d<100 \mathrm{~nm}$ and almost remains unchanged when $100 \mathrm{~nm} \leq d \leq 400$ $\mathrm{nm}$, while $R_{\mathrm{Si}}$ shows an oscillative behaviour due to the interference effect of a dielectric layer.

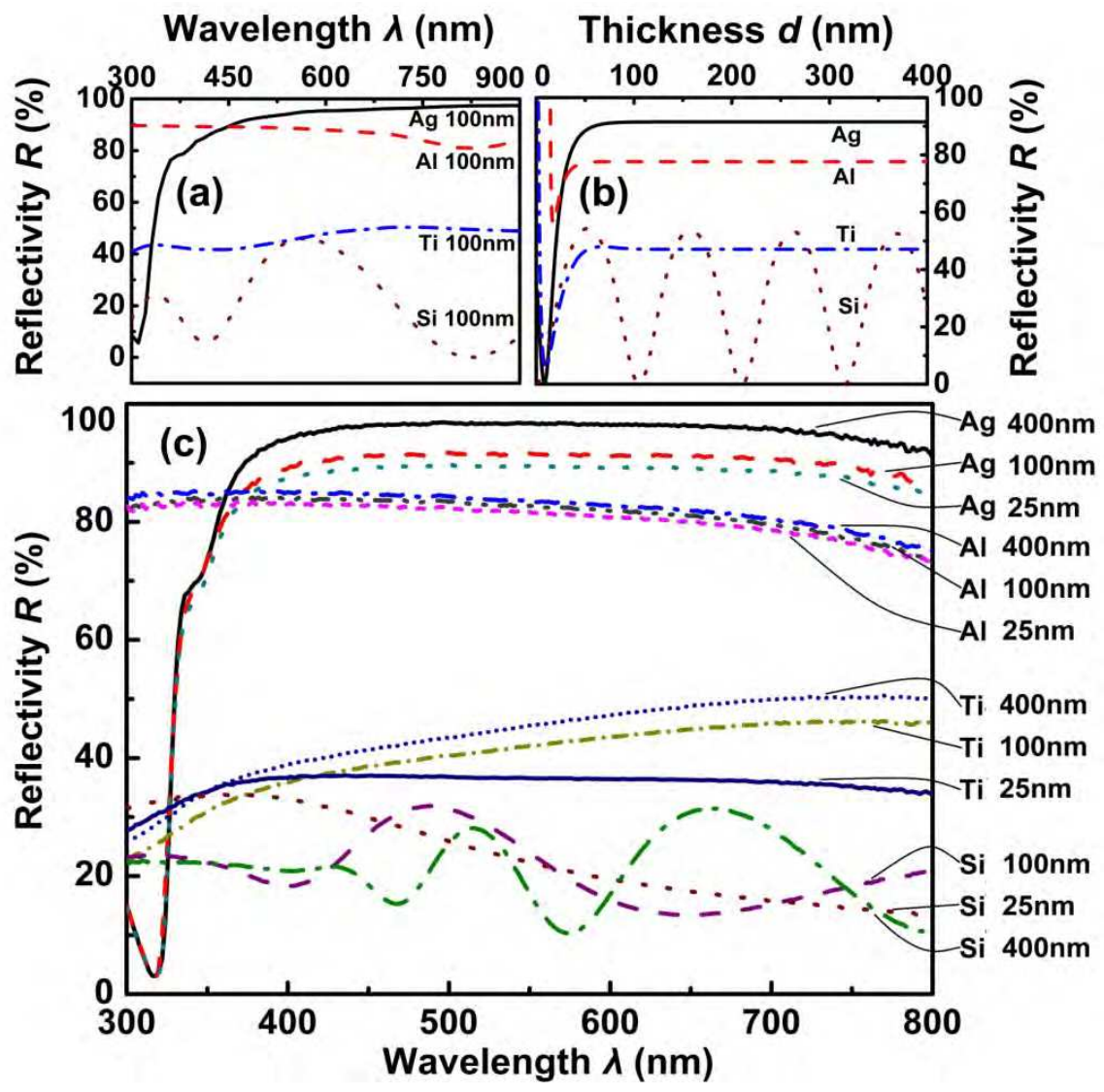

Fig. 5. (a) Calculated reflectivity $\mathrm{R}$ of thin $\mathrm{Ag}, \mathrm{Al}, \mathrm{Si}$ and Ti films at different wavelengths $\lambda$ with film thickness of $100 \mathrm{~nm}$; b) calculated reflectivity $R$ of thin $\mathrm{Ag}, \mathrm{Al}, \mathrm{Si}$ and Ti films with different thicknesses $d$ at $\lambda_{0}=785 \mathrm{~nm}$; c) experimentally obtained reflectivity spectra of thin $\mathrm{Ag}, \mathrm{Al}, \mathrm{Si}$ and $\mathrm{Ti}$ films with different thicknesses.

We deposited thin $\mathrm{Ag}, \mathrm{Al}, \mathrm{Si}$ and Ti films, all with thickness $d=25,100$, and $400 \mathrm{~nm}$, respectively, to achieve different reflectivity. All depositions were carried out in a customdesigned electron-beam deposition system. ${ }^{16]}$ Before the deposition, the glass slide substrates were cleaned by piranha solution $\left(\mathrm{H}_{2} \mathrm{SO}_{4}: \mathrm{H}_{2} \mathrm{O}_{2}=4: 1\right.$ in volume). The pellets of source materials, $\mathrm{Ag}$, $\mathrm{Al}$, $\mathrm{Ti}$, with $99.99 \%$ purity, were purchased from Kurt J. Lesker Company, and Si with $99.9999 \%$ purity was purchased from Alfa Aesar Company. The film thickness was monitored in situ by a quartz crystal microbalance (QCM) facing toward the vapour source. After the deposition, the reflectivity of the deposited thin films was measured by an Ultraviolet-Visible Spectrophotometer (UV-Vis) double beam spectrophotometer with an integrating sphere (Shimadzu UV-Vis 2450). Figure 1(c) shows 
the reflectivity spectra of the twelve thin films obtained. The shapes of the reflection spectra are qualitatively consistent with those predicted by the calculations, as shown in Figs. 1(a) and (b). At the same wavelength, in general, $R_{\mathrm{Ag}}>R_{\mathrm{Al}}>R_{\mathrm{Ti}}>R_{\mathrm{Si}}$. In the visible wavelength region, the reflectivity of $\mathrm{Ag}, \mathrm{Al}$ and $\mathrm{Ti}$ increases with the thickness $d$, while $\mathrm{Si}$ demonstrates an oscillating behaviour.

The twelve deposited planar thin film samples were then loaded into another customdesigned electron-beam evaporation system for Ag nanorod deposition through the socalled oblique angle deposition (OAD).[16, 29, 37] In this deposition, the background pressure was $1 \times 10^{-7}$ Torr and the substrate holder was rotated so that the deposition flux was incident onto the thin films with an angle $\theta=86^{\circ}$ with respect to the surface normal of the substrate holder. The Ag nanorod arrays were formed through a self-shadowing effect.[16, 29, 37] During the deposition, the Ag deposition rate was monitored by a QCM directly facing the incident vapour. The deposition rate was fixed at $0.3 \mathrm{~nm} / \mathrm{s}$ and the deposition ended when the QCM read $2000 \mathrm{~nm}$ (our optimized condition).
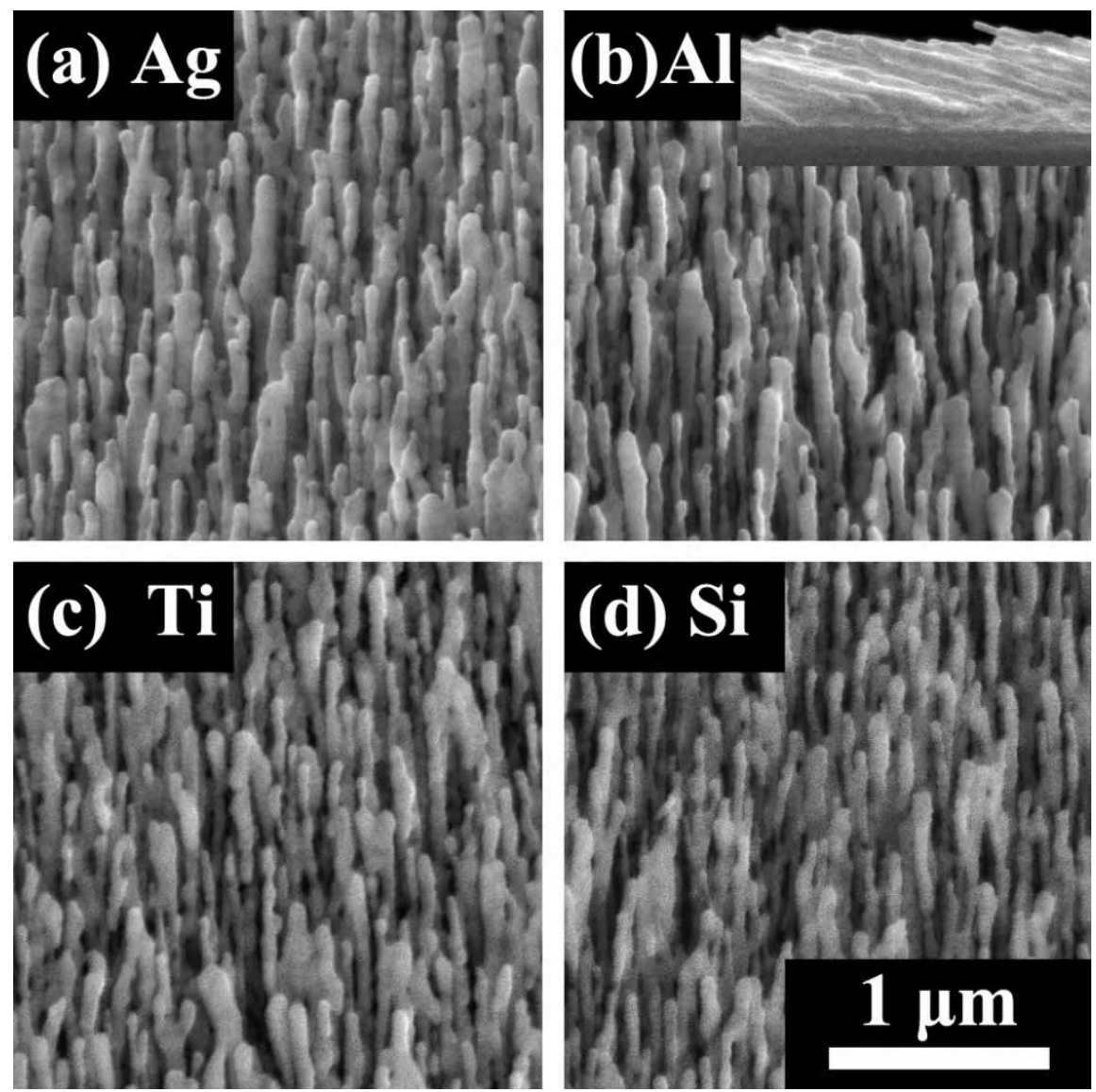

Fig. 6. Representative SEM images of Ag nanorod arrays on $100 \mathrm{~nm}$ underlayer thin films with different materials: (a) Ag; (b) $\mathrm{Al}$; (c) $\mathrm{Ti}$; (d) Si. All the figures have the same scale bar. 
The morphologies of the Ag nanorod arrays on different thin film substrates were characterized by a scanning electron microscope (SEM, FEI Inspect F). The typical topview SEM images are shown in Fig. 6 and they all look very similar. From the crosssection and top-view SEM images, the length $L$, diameter $D$ and separation $S$ of these $\mathrm{Ag}$ nanorods on different planar thin films are obtained statistically: $L_{\mathrm{Ag}}=940 \pm 70 \mathrm{~nm}$, $D_{\mathrm{Ag}}=90 \pm 10 \mathrm{~nm}, S_{\mathrm{Ag}}=140 \pm 30 \mathrm{~nm} ; L_{\mathrm{Al}}=950 \pm 50 \mathrm{~nm}, D_{\mathrm{Al}}=90 \pm 10 \mathrm{~nm}, S_{\mathrm{Al}}=140 \pm 30$ $\mathrm{nm} ; L_{\mathrm{Si}}=900 \pm 50 \mathrm{~nm}, D_{\mathrm{Si}}=80 \pm 10 \mathrm{~nm}, S_{\mathrm{Si}}=130 \pm 20 \mathrm{~nm}$; and $L_{\mathrm{Ti}}=930 \pm 60 \mathrm{~nm}, D_{\mathrm{Ti}}=90$ $\pm 10 \mathrm{~nm}, S_{\mathrm{Ti}}=130 \pm 20 \mathrm{~nm}$, respectively. The Ag nanorod tilting angles $\beta$ were measured to be about $73^{\circ}$ with respect to substrate normal, which are consistent with our previous results. $[16,29,37]$ These structure parameters are very close to one another, implying that the Ag nanorod arrays deposited on different thin film substrates are statistically the same. The SERS response of these Ag nanorod substrates were evaluated under identical conditions: A $2 \mu \mathrm{L}$ droplet of a Raman probe molecule, trans-1, 2- bis (4-pyridyl) ethylene (BPE) with a concentration of $10^{-5} \mathrm{M}$, was uniformly dispersed onto the $\mathrm{Ag}$ nanorod substrates. The SERS spectra were recorded by the HRC-10HT Raman Analyzer from Enwave Optronics Inc., with an excitation wavelength of $\lambda_{0}=785 \mathrm{~nm}$, a power of 30 $\mathrm{mW}$ and an accumulation time of $10 \mathrm{~s}$.

Figure 7(a) shows the representative BPE SERS spectra obtained at $\lambda_{0}=785 \mathrm{~nm}$ from the $\mathrm{Ag}$ nanorod arrays on thin $\mathrm{Ag}, \mathrm{Al}, \mathrm{Si}$ and Ti film underlayers (thickness $d=100 \mathrm{~nm}$ ). Each spectrum is an average of at least 15 different spectra taken at different spots on the substrates. All of them show the three main Raman bands of BPE, $\Delta v=1639,1610$, and $1200 \mathrm{~cm}^{-1}$, which can be assigned to the $\mathrm{C}=\mathrm{C}$ stretching mode, aromatic ring stretching mode and in-plane ring mode, respectively.[38] The SERS intensity of the Ag nanorods grown on thin Ag film are higher than others and the SERS intensity of the Ag nanorods on Al film is larger than that on Ti film. The Ag nanorods on Si film show the smallest SERS intensity. According to Fig. 5(c), this seems to follow a trend: the larger the underlayer reflectivity, the larger the SERS intensity. To quantitatively compare the SERS response of these substrates, the Raman peak intensity $I_{1200}$ at $\Delta v=1200 \mathrm{~cm}^{-1}$ is analyzed.

Figure $7(\mathrm{~b})$ plots the SERS intensity $I_{1200}$ versus the reflectivity $R$ of the underlayer thin films at $\lambda_{0}=785 \mathrm{~nm}$. The error bar for the Raman intensity is the standard deviation from 15 or more measurements from multiple sampling spots on the same substrates and the error bar for the reflectivity data is calculated from multiple reflectivity measurements at $\lambda_{0}=785 \mathrm{~nm}$. In Fig. 7(b), the SERS intensity and reflectivity follow a linear relationship: when the reflectivity of the underlayer increases, the SERS enhancement factor increases. This linear relationship of the underlayer reflectivity and SERS intensity can be explained by a modified Greenler's model developed by Liu et al. [34] Greenler's model is proposed through classical electrodynamics to explain the effects of the incident angles and polarization, and the collecting angle on the Raman scattering from a molecule adsorbed on a planar surface. [32] The modified Greenler's model extended the Greenler's model from a planar surface to Ag nanorod substrates and considered the effect of the underlying substrate.[34] The main point of the modified Greenler's model is to consider the conditions of both the incident and scattering fields near the molecule absorbed on a nanorod to calculate the enhancement.

Assuming that relative Raman intensity $\eta$ is the ratio of the total Raman scattering power to incident light power, according to the modified Greenler's model, $\eta$ excited by an unpolarized light can be explicitly expressed as ${ }^{[34]}$ 


$$
\begin{aligned}
& \eta=<\mathrm{E}_{\text {Raman }}^{2}>/<\mathrm{E}_{\text {incident }}^{2}> \\
& =\frac{1}{2}\left\{\left[1+\mathrm{R}_{\mathrm{p}}+\mathrm{n}_{2}^{4} \mathrm{R}_{\mathrm{p}}^{\prime} \cos \delta_{\mathrm{p}} \cos 2(\varphi-\beta)+2 \mathrm{n}_{2}^{2} \mathrm{R}_{\mathrm{p}}^{\prime \frac{1}{2}} \cos \left(\delta_{\mathrm{p}}^{\prime}+2 \pi \Delta / \lambda\right) \sin 2 \beta\right.\right. \\
& \left.+2 \mathrm{n}_{2}^{2} \mathrm{R}_{\mathrm{p}}^{\frac{1}{2}} \mathrm{R}_{\mathrm{p}}^{\frac{1}{12}} \sin 2 \varphi \cos \left(\delta_{\mathrm{p}}^{\prime}+2 \pi \Delta / \lambda-\delta_{\mathrm{p}}\right)\right]\left(1+\mathrm{R}_{\mathrm{p}}+2 \sqrt{\mathrm{R}_{\mathrm{p}}} \cos \delta_{\mathrm{p}}\right) \cos ^{2}(\varphi-\beta) \\
& \left.+\left[1+\mathrm{n}_{2}^{4} \mathrm{R}_{\mathrm{s}}^{\prime}+2 \mathrm{n}_{2}^{2} \mathrm{R}_{\mathrm{s}}^{\frac{1}{12}} \cos \left(\delta_{\mathrm{s}}^{\prime}+2 \pi \Delta / \lambda\right)\right]\right\}
\end{aligned}
$$

where $R_{\mathrm{p}}$ and $R_{\mathrm{s}}$ are the reflectivity of $p$ - and s-polarized lights by the Ag nanorod surface, and $R_{p}^{\prime}$ and $R_{s}^{\prime}$ are the reflectivity of $p$ - and s-polarized components by the underlayer thin film; $n_{2}$ is complex refractive index of $\mathrm{Ag}$, and $n_{2}=0.03+5.242 i$ (for $\lambda_{0}=$ $785 \mathrm{~nm}) ; \varphi$ is the light incident angle, and $\beta$ is the Ag nanorod tilting angle; $\Delta=d(1+\cos$ $2 \varphi) / \cos \varphi$, where $d$ is the thickness of Ag nanorod layer; $\delta_{\mathrm{p}}, \delta_{\mathrm{s}}, \delta_{\mathrm{p}}^{\prime}$, and $\delta_{\mathrm{s}}^{\prime}$ are the reflectivity phase shifts of $p$ - and s-polarization E-fields from $\mathrm{Ag}$ nanorods and underlayer thin film, defined as

$$
\begin{gathered}
\delta_{\mathrm{p}}=\tan ^{-1}\left[\operatorname{Im}\left(\mathrm{r}_{\mathrm{p}}\right) / \operatorname{Re}\left(\mathrm{r}_{\mathrm{p}}\right)\right], \delta_{\mathrm{s}}=\tan ^{-1}\left[\operatorname{Im}\left(\mathrm{r}_{\mathrm{s}}\right) / \operatorname{Re}\left(\mathrm{r}_{\mathrm{s}}\right)\right], \\
\delta_{\mathrm{p}}^{\prime}=\tan ^{-1}\left[\operatorname{Im}\left(\mathrm{r}_{\mathrm{p}}^{\prime}\right) / \operatorname{Re}\left(\mathrm{r}_{\mathrm{p}}^{\prime}\right)\right], \delta_{\mathrm{s}}^{\prime}=\tan ^{-1}\left[\operatorname{Im}\left(\mathrm{r}_{\mathrm{s}}^{\prime}\right) / \operatorname{Re}\left(\mathrm{r}_{\mathrm{s}}^{\prime}\right)\right]
\end{gathered}
$$

By setting the light incident angle $\varphi=0^{\circ}$, the Ag nanorod tilting angle $\beta=73^{\circ}$, the thickness of Ag layer $d=300 \mathrm{~nm}$, the relative Raman intensity $\eta$ as a function of the underlayer reflectivity $R$ at $\lambda_{0}=785 \mathrm{~nm}$ is calculated and plotted in Fig. 7(c). It shows that the $\eta$ indeed increases linearly with $R$, which is in very good agreement with our experimental data shown in Fig. 7(b). Therefore, the underlayer reflectivity is one significant parameter to consider for improving the SERS response of multilayer substrates.

Both our experiments and the modified Greenler's model demonstrate that the higher the underlayer reflectivity, the higher the SERS intensity for the Ag nanorod based SERS substrates. Accordingly, in order to further improve the SERS response of the Ag nanorod substrates, one can further increase the reflectivity of the underlayers through a proper surface coating such as multilayer dielectric coating.[39]

\section{Detecting trace amount PCBs by SERS method}

With the highly sensitive SERS substrates described before, one can detect trace amount organic molecules by the SERS method.

SERS is extremely sensitive in water solutions, for water does not have any Raman peaks. When detecting organic pollutants in nonaqueous systems, we use volatile organic solvents, such as acetone, to dilute pollutants. As the organic solvent shows high Raman background, we need to make the solvent volatilizated completely before SERS measurement.

The powders of 2, 3, 3', 4, 4'-pentachlorinated biphenyl used in this study were commercially available from the AccuStandard Company. Since there is no Raman data of 2, 3, 3', 4, 4'- pentachlorinated biphenyl reported, we first measured its Raman spectrum and that of acetone, for comparison, see Figure 8(a). To clearly show most characteristic peaks of 2, 3, 3', 4, 4'-pentachlorinated biphenyl, the Raman spectrum was 
plotted in two regions of 300 to $1000 \mathrm{~cm}^{-1}$ and 1000 to $1700 \mathrm{~cm}^{-1}$ respectively, see Figures $11(b)$ and 11(c). From the figures one sees that the strongest peaks are located at 342, 395, 436, 465, 495, 507, 517, 598, 679, 731, 833, 891, 1032, 1136, 1179, 1254, 1294, 1573, and 1591 $\mathrm{cm}^{-1}$, respectively; while for acetone the characteristic peaks are at 530, 786, 1065, 1220, 1428 and $1709 \mathrm{~cm}^{-1}$, respectively. It is suggested that 2, 3, 3', 4, 4'-pentachlorinated biphenyl is distinguishable from acetone and that acetone can be used as the solvent for the SERS measurements, as 2, 3, 3' , 4, 4' -pentachlorinated biphenyl is not soluble in water.
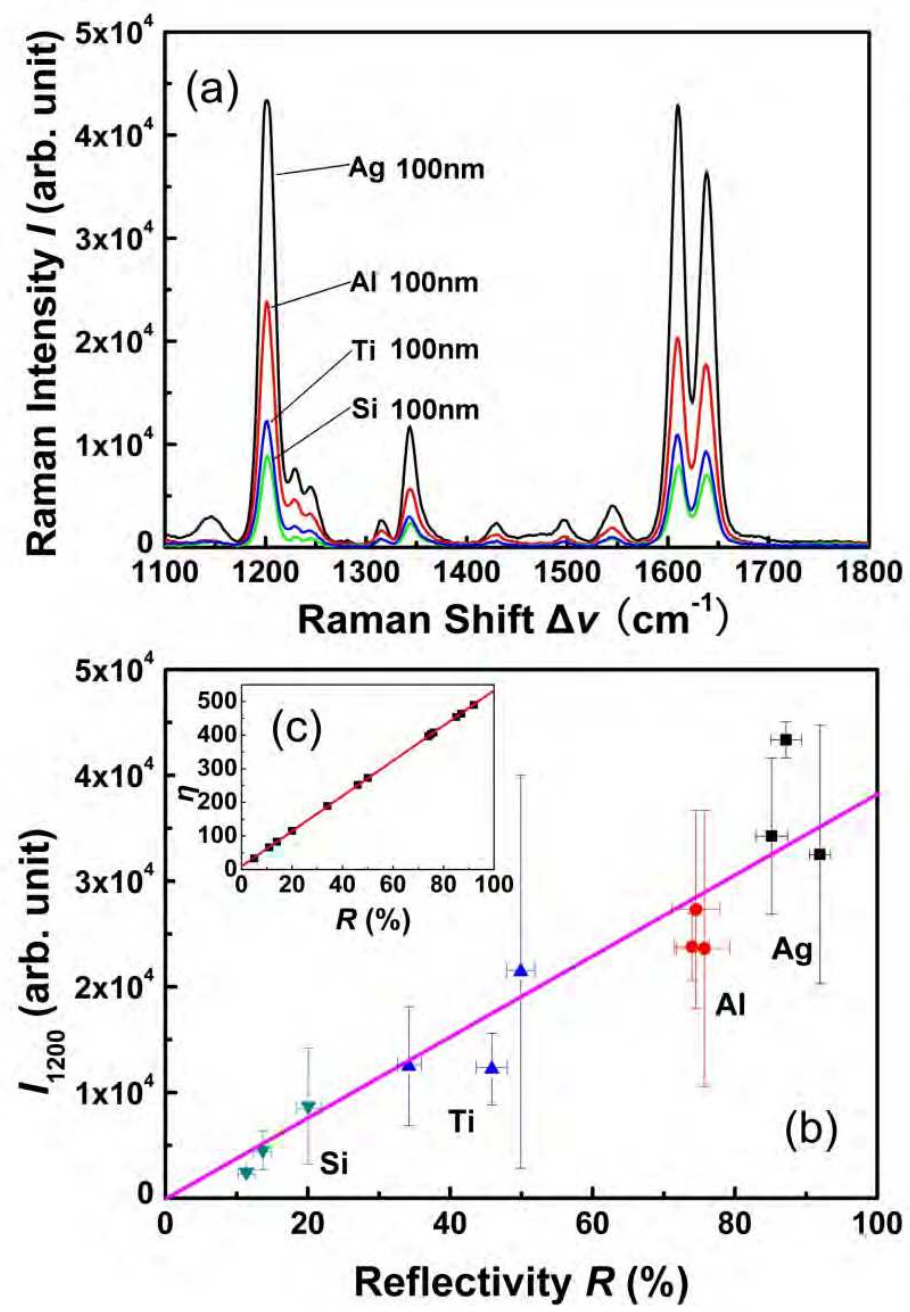

Fig. 7. (a) BPE SERS spectra obtained from Ag nanorod arrays deposited on $100 \mathrm{~nm}$ thin $\mathrm{Ag}, \mathrm{Al}, \mathrm{Si}$ and Ti film underlayers; (b) the plot of experimental Raman intensity as a function of underlayer reflectivity at $\lambda_{0}=785 \mathrm{~nm}$. Different symbol groups represent different kinds of substrates. (c) The plot of the enhanced Raman intensity ratio $\eta$ as a function of underlayer reflectivity calculated by the modified Greenler's model. 

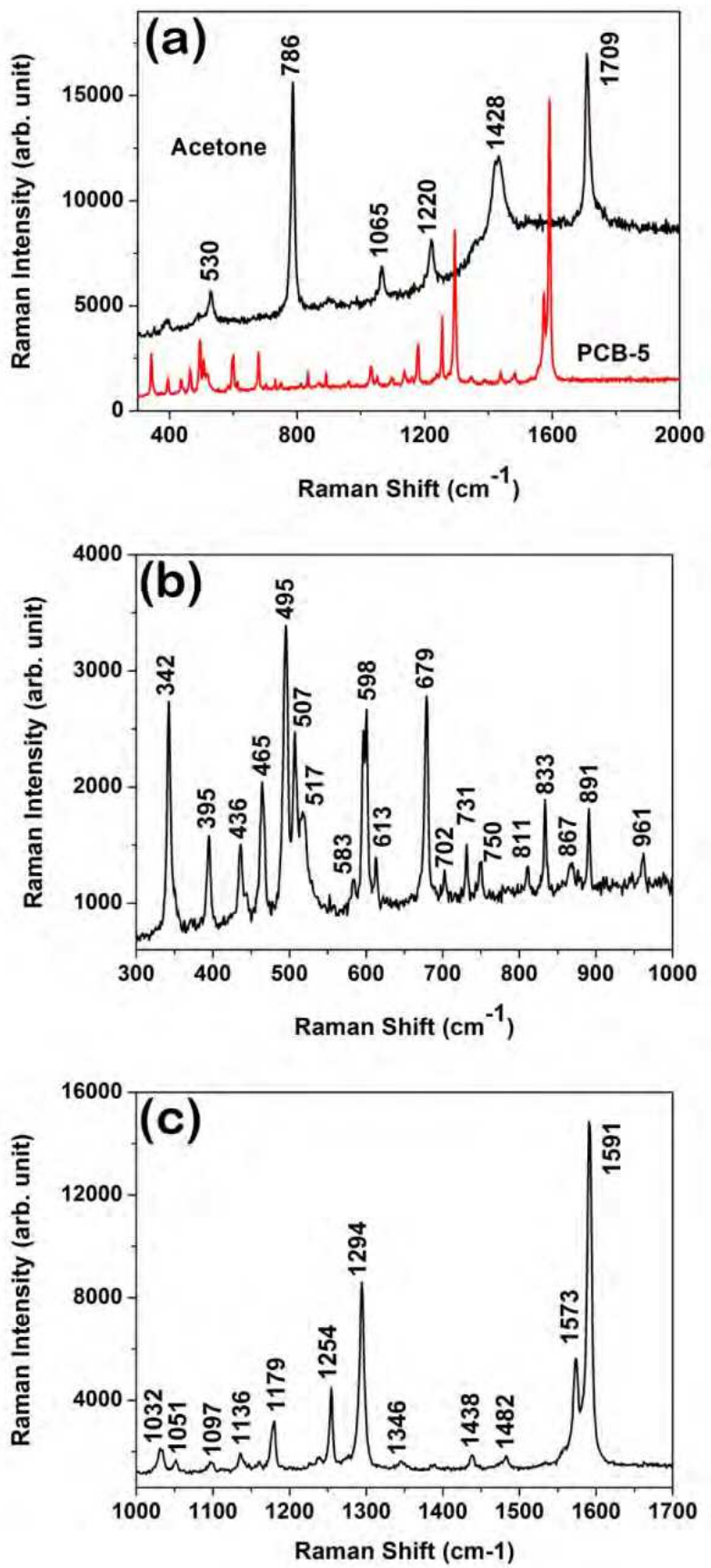

Fig. 8. (a) Comparison of Raman spectra of PCB-5 powders and acetone; (b) and (c) show details of the Raman spectrum of PCB- 5 powders. 
Because the SERS sensitivity is also dependent on the sample treatment, we employed in this study a very simple method to prepare SERS samples, i.e. dropping a small volume $(\sim 0.5 \mathrm{uL})$ of solutions of 2,3,3',4, 4'-pentachlorinated biphenyl in acetone on Ag nanorods using a top single channel pipettor and then blowing away the acetone with a continuous, gentle nitrogen blow. Figure 9(a) shows the Raman spectra of 2, 3, 3', 4, 4'pentachlorinated biphenyl dissolved in acetone at concentrations of $10^{-4}$ to $10^{-10} \mathrm{~mol} / \mathrm{L}$, respectively. The accumulation time of each Raman spectrum was 50 seconds and we used only $1 \%$ laser power to avoid changing of pentachlorinated biphenyl. When the small volume $(\sim 0.5 \mathrm{uL})$ of solutions of 2, 3, 3', 4, 4'-pentachlorinated biphenyl was dropped on Ag nanorods, it became a circular spot with diameter of about $4 \mathrm{~mm}$. The Raman spectrum was accumulated from a 2 um diameter circular area on the substrates. Therefore, for the solution at concentration of $10^{-10} \mathrm{~mol} / \mathrm{L}$, only about ten $2,3,3^{\prime}, 4,4^{\prime}$ pentachlorinated biphenyl molecules $\left(2^{*} 10^{-23} \mathrm{~mol}\right)$ would be accumulated in SERS; if that was at concentration of $10-8 \mathrm{~mol} / \mathrm{L}$, about 1000 molecules $\left(2^{*} 10^{-21} \mathrm{~mol}\right)$ would be accumulated and so on.

One sees that the Raman peaks of $10^{-4} \mathrm{~mol} / \mathrm{L}$ PCB-5 solution located at 342, 495, 598, 679, $1032,1136,1179,1254,1294,1573$ and $1591 \mathrm{~cm}^{-1}$ march the Raman peaks of powder PCB-5 very well, this is quite different from the characteristic peaks of acetone. The peak around $1390 \mathrm{~cm}^{-1}$ represents disordered and amorphous carbon on the substrates. Figure 9(b) shows the SERS spectra of 10-8 mol/L PCB-5. Peaks located at 495, 1032, 1294, 1573 and $1591 \mathrm{~cm}^{-1}$ can march the Raman peaks of powder PCB-5. It indicates that the peaks shown in Figure 9(a) and (b) are the characteristic peaks of dissolved PCB-5, and PCB-5 with a concentration of $10^{-8} \mathrm{~mol} / \mathrm{L}$ can be detected by the SERS method in the authors' work.

Large scale arrays of aligned and well separated single crystalline Ag nanorods on planar silicon substrate can be fabricated by GLAD method and these Ag films can be used as SERS substrates. With these substrates 2, 3, 3', 4, 4'- PCB-5 molecules were detected even at a concentration of $10^{-8} \mathrm{~mol} / \mathrm{L}$ by the SERS method, which indicates that trace amount of PCBs can be detected by the SERS method with Ag nanorods as SERS substrates.[45]

\section{Rapid recognition of isomers and homologues of PCBs at trace levels by SERS}

Detecting trace amount PCBs by the SERS method is introduced in section 4, but simple detection is not enough for organic pollutant detection, one also needs to distinguish kinds of organic pollutants from each other.

Furthermore, isomers and homologues of organic pollutants are hard to distinguish especially in trace amounts - due to the similarities in their physical and chemical properties. The SERS method with silver nanorods as a substrate can be used to identify the Raman characteristics of isomers of monochlorobiphenyls and recognize these compounds, even at trace levels.

The Raman spectra of biphenyl, 2-, 3- and 4-chlorobiphenyls were measured by a Renishaw Raman 100 spectrometer using a $633 \mathrm{~nm}$ He-Ne laser as the excitation source at room temperature. Powders of these compounds are commercially available from the AccuStandard Company. Simulation of these Raman spectra was performed using the Gaussian 03 programme package with the density functional theory, to better understand the vibrational modes observed and figure out fingerprints of these 
compounds. For the SERS measurements, powders of chlorobiphenyl were dissolved in acetone to concentrations from $10^{-4}$ to $10^{-10} \mathrm{~mol} / \mathrm{L}$. The substrates were Ag nanorods prepared by electron beam deposition. The deposition of the Ag nanorods was described as aforementioned. A small volume of the solutions $(\sim 0.5 \mu \mathrm{L})$ was dropped on the surface of Ag nanorods and acetone was blown away using a nitrogen flow.
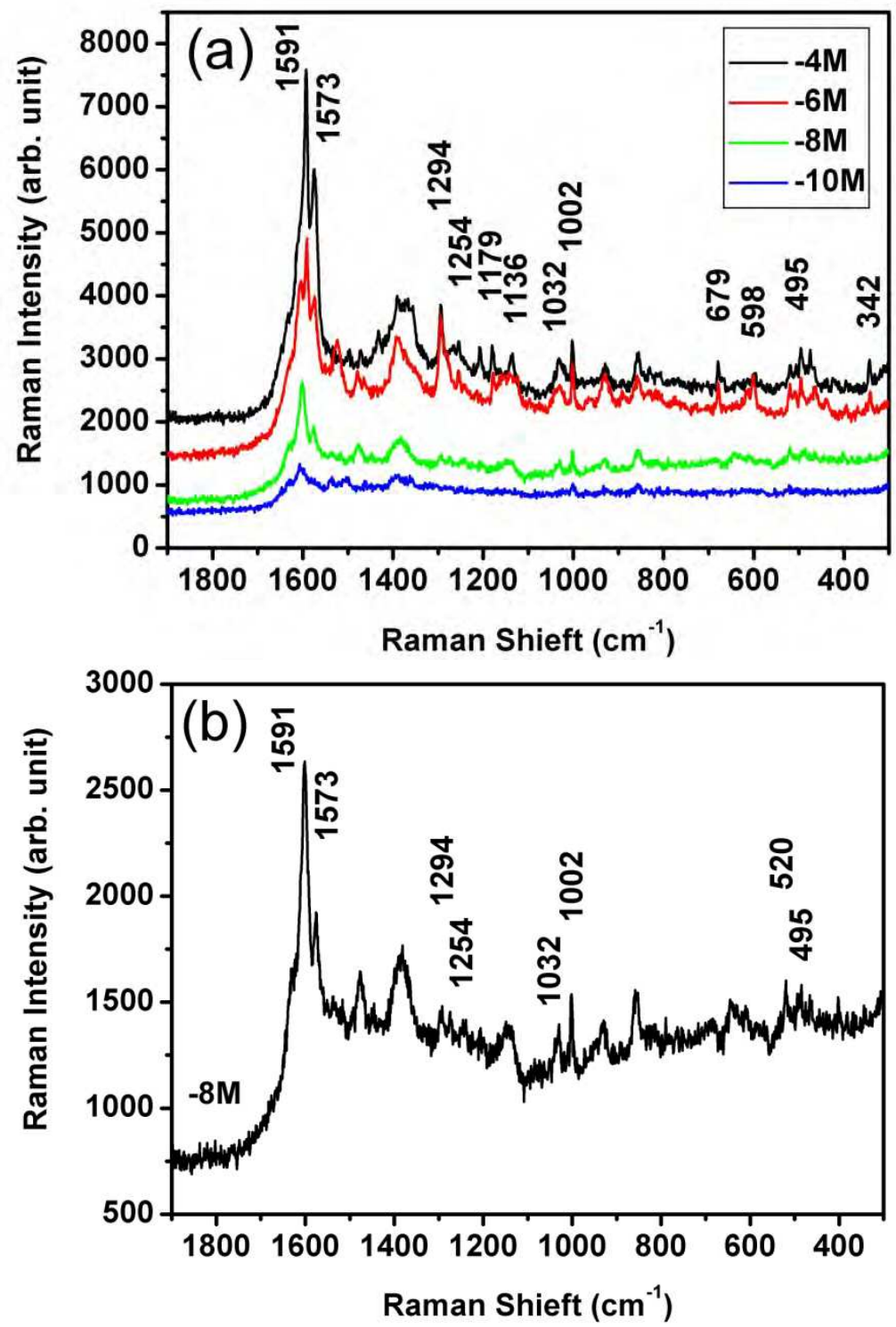

Fig. 9. (a) SERS spectra of PCB-5 dissolved in acetone with various concentrations; (b) SERS spectrum of PCB-5 in acetone at a concentration of 10-8 $\mathrm{mol} / \mathrm{L}$. 
Figures 10 (a), (b), (c) and (d) show the measured Raman spectrum of biphenyl, 2-, 3and 4-chlorobiphenyl, respectively. One sees that the four derivatives have strong peaks at $\sim 3065,1600,1280,1030$ and $1000 \mathrm{~cm}^{-1}$, demonstrating the common feature of biphenyl and its derivatives. One may also notice the differences among the Raman spectra of the four derivatives. For example, (1) biphenyl, 3- and 4-chlorobiphenyl have strong Raman peaks around $1276 \mathrm{~cm}^{-1}$, while the peak for 2-chlorobiphenyl was at $1297 \mathrm{~cm}^{-1}$; (2) biphenyl has a strong peak at $738 \mathrm{~cm}^{-1}, 2$ - and 4-chlorobiphenyl have strong peaks at $760 \mathrm{~cm}^{-1}$, but the peak for 3-chlorobiphenyl was negligible; (3) both 2- and 3chlorobiphenyl have strong peaks around $\sim 680 \mathrm{~cm}^{-1}$, while biphenyl and 4chlorobiphenyl have no visible peak nearby; (4) only 2-chlorobiphenyl has a strong peak at $\sim 432 \mathrm{~cm}^{-1}$. The above features might be used to detect and distinguish biphenyl, 2-, 3 and 4-chlorobiphenyl.

To gain a clear understanding of these features, we performed simulations using the Gaussian 03 programme package with the density functional theory. The simulations were carried out with the Becke's three-parameter hybrid method using the Lee-yangParr correlation functional (B3LYP) and the LANL2DZ basis set.[46] The Gaussian View was used to input investigated compounds' data visually. The $\pi$ bond length of the benzene ring was set to be $1.409 \AA$, the $\sigma$ bond length between $\mathrm{C}$ and $\mathrm{H}$ atoms was set to be $1.088 \AA$ and the o bond length between $\mathrm{C}$ and $\mathrm{Cl}$ atoms was set to be $1.760 \AA$.
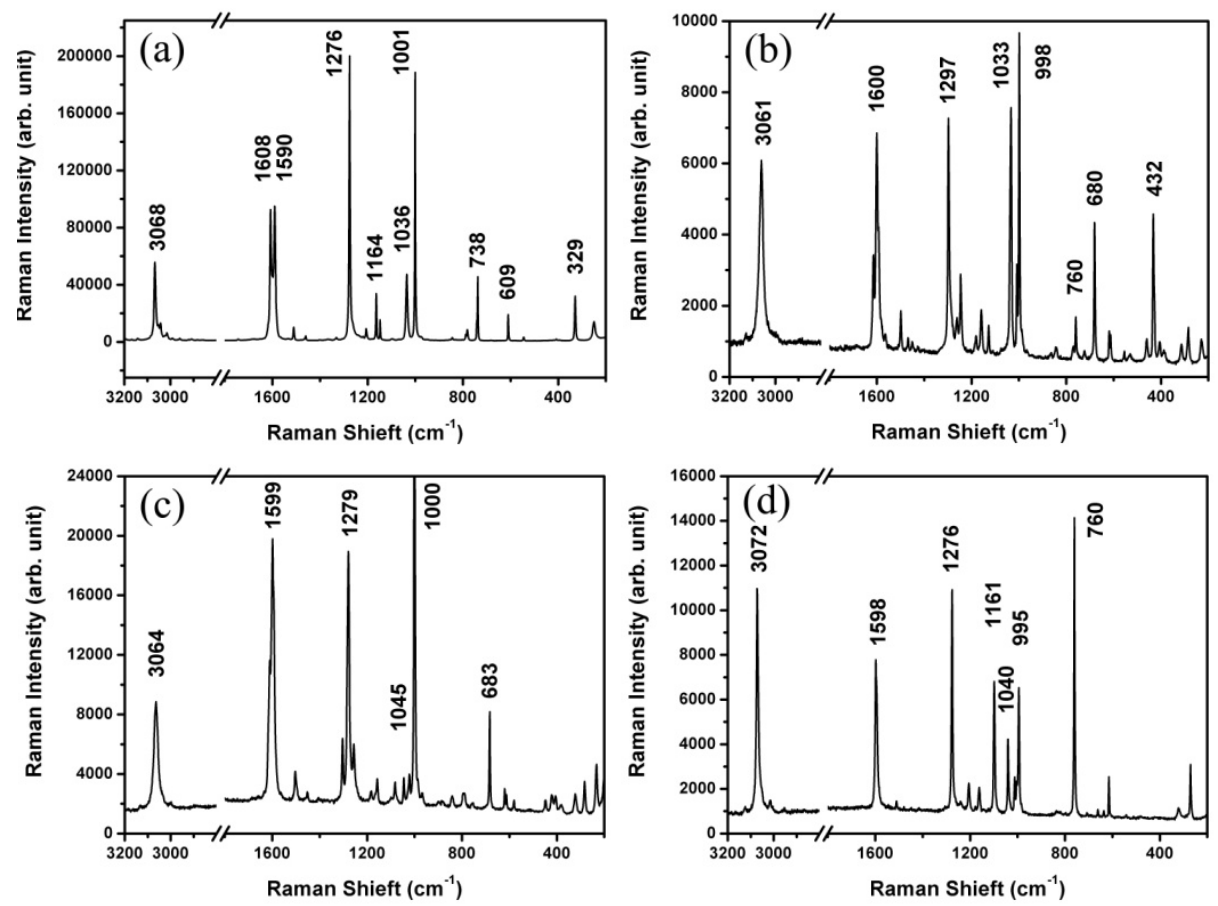

Fig. 10. Raman spectra of (a) biphenyl; (b) 2-chlorobiphenyl; (c) 3-chlorobiphenyl; and (d) 4-chlorobiphenyl, measured using powders commercially available from the AccuStandard Company. 
Table I lists major vibrational modes of the four derivatives obtained by the above simulations. The common features of their Raman spectra at 3065, 1600, 1280, 1030 and $1000 \mathrm{~cm}^{-1}$, seen in Figure 10, can be attributed to the C-H stretching mode $\left(\sim 3100 \mathrm{~cm}^{-1}\right)$, the ring CCC stretching mode $\left(\sim 1650 \mathrm{~cm}^{-1}\right)$, the C-C bridge bond stretching mode $(\sim$ $\left.1280 \mathrm{~cm}^{-1}\right)$, the $\mathrm{C}-\mathrm{H}$ bending in-plane mode $\left(1050\right.$ to $\left.1100 \mathrm{~cm}^{-1}\right)$ and the CCC trigonal breathing mode $\left(\sim 1000 \mathrm{~cm}^{-1}\right)$, respectively.

\begin{tabular}{|l|c|c|c|c|}
\hline \multicolumn{1}{|c|}{ Vibrational Model } & $\begin{array}{c}\text { Raman } \\
\text { Shift /cm-1 }\end{array}$ & $\begin{array}{c}\text { Raman Int.of 2- } \\
\text { chlorobiphenyl }\end{array}$ & $\begin{array}{c}\text { Raman Int.of 3- } \\
\text { chlorobiphenyl }\end{array}$ & $\begin{array}{c}\text { Raman Int.of 4- } \\
\text { chlorobiphenyl }\end{array}$ \\
\hline CH stretching & 3100 & 511 & 359 & 351 \\
\hline CCC stretching & 1650 & 31 & 34 & 38 \\
\hline CC-bridge stretching & 1280 & 50 & 50 & 62 \\
\hline CH bending in-plane & 1050 & 46 & 22 & 15 \\
\hline trigonal breathing & 1000 & 34 & 44 & 27 \\
\hline $\begin{array}{l}\text { CCC bending in-plane } \\
\text { (1-4 direction) }\end{array}$ & 760 & 3 & 4 & 23 \\
\hline $\begin{array}{l}\text { CCC bending in-plane } \\
\text { (3-6 direction) }\end{array}$ & 680 & 11 & 8 & 7 \\
\hline $\begin{array}{l}\text { CCC bending in-plane } \\
\text { (2-5 direction) }\end{array}$ & 460 & 13 & 0 & 0 \\
\hline
\end{tabular}

Table 1. Major simulated vibrational modes for 2-, 3- and 4-chlorobiphenyl.

One sees that due to the replacement of the $\mathrm{H}$ by $\mathrm{Cl}$ atom, the $\mathrm{CCC}$ bending (ring deformation) in-plane modes $\left(\sim 760 \mathrm{~cm}^{-1}, 680 \mathrm{~cm}^{-1}\right.$ and $\left.460 \mathrm{~cm}^{-1}\right)$ changed differently for 2-, 3- and 4-chlorobiphenyl. Figures 11 (a), (b) and (c) show respectively the strong CCC bending in-plane mode for 2-, 3- and 4-chlorobiphenyl. It is seen that for the 2chlorobiphenyl, the 2-5 direction CCC bending at $460 \mathrm{~cm}^{-1}$ is the strongest one, the 3-6 direction CCC bending at $680 \mathrm{~cm}^{-1}$ has a similar intensity, while the 1-4 direction bending at $760 \mathrm{~cm}^{-1}$ is weak. For 3-chlorobiphenyl, the 2-5 direction bending mode is negligible, the 3-6 direction bending mode is strong, while the 1-4 direction bending mode is weak. For 4chlorobiphenyl, the 2-5 direction bending mode is negligible, the 3-6 direction bending mode is weak, while the 1-4 direction bending mode is strong. These results are in agreement with the experimental measurements and suggest that these features in the CCC bending in-plane modes can be used to recognize the three homologues.

The substrate used in the SERS measurements was Ag nanorods prepared by the electron beam deposition technique. Powders of 2-, 3- and 4-chlorobiphenyl were dissolved in acetone and diluted into solutions with a concentration ranging from $10^{-4}$ to $10^{-10} \mathrm{~mol} / \mathrm{L}$. A small volume $(0.5 \mu \mathrm{L})$ of these solutions was dropped on Ag nanorods and the acetone was blown away using a gentle nitrogen flow. Figures 12 (a), (b) and (c) show respectively the SERS spectra of the 2-, 3- and 4-chlorobiphenyl, at various concentrations. The accumulation time of each spectrum was fixed at 30 seconds per 100 $\mathrm{cm}^{-1}$ and we used only $10 \%$ laser power $(0.47 \mathrm{~mW})$ to avoid radiation damage. From these figures we notice that the characteristic Raman peaks are all clearly observed for three homologues, even at a concentration of $10^{-8} \mathrm{~mol} / \mathrm{L}$, suggesting that the SERS technique is able to detect chlorobiphenyls even at such a low concentration. 


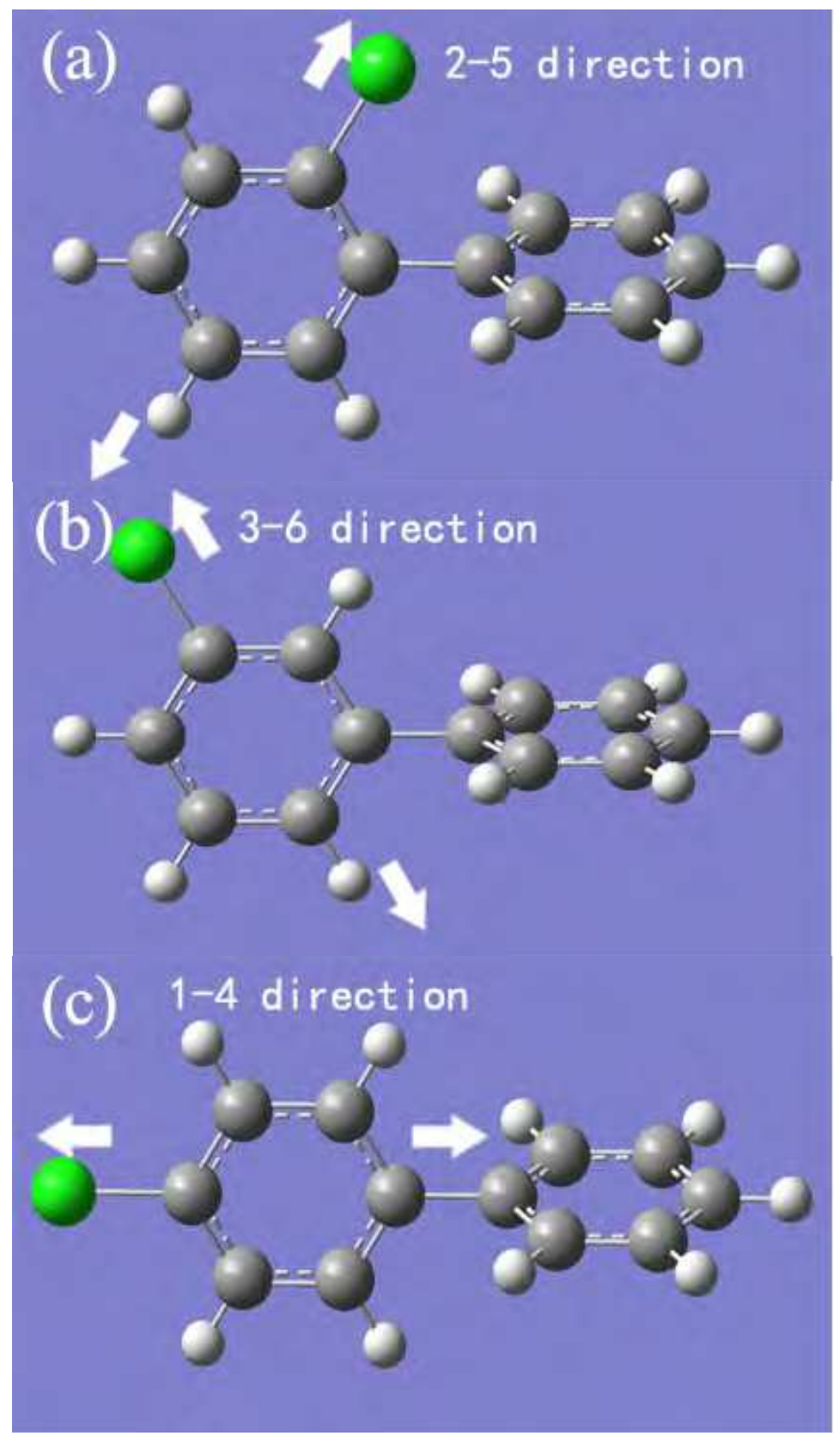

Fig. 11. The strong ring deformation in-plane modes for the three homologues of chlorobiphenyl. (a) 2-chlorobiphenyl; (b) 3-chlorobiphenyl; and (c) 4-chlorobiphenyl. 
Figure $12(d)$ compares SERS spectra of the three homologues at a concentration of 10-6 $\mathrm{mol} / \mathrm{L}$. One sees that at this concentration the three spectra show clearly the common features as mentioned above around 1600, 1280, 1030 and $1000 \mathrm{~cm}^{-1}$ (the $3100 \mathrm{~cm}^{-1}$ was not measured). The spectra also clearly show the characteristic Raman peaks for three homologues, i.e. the difference in the CCC bending (ring deformation) in-plane modes caused by the $\mathrm{Cl}$ atom replacement. These suggest that by using $\mathrm{Ag}$ nanorods as substrates, the SERS technique is capable of detecting chlorobiphenyls at trace amounts and is capable of recognizing the homologues at small concentrations.
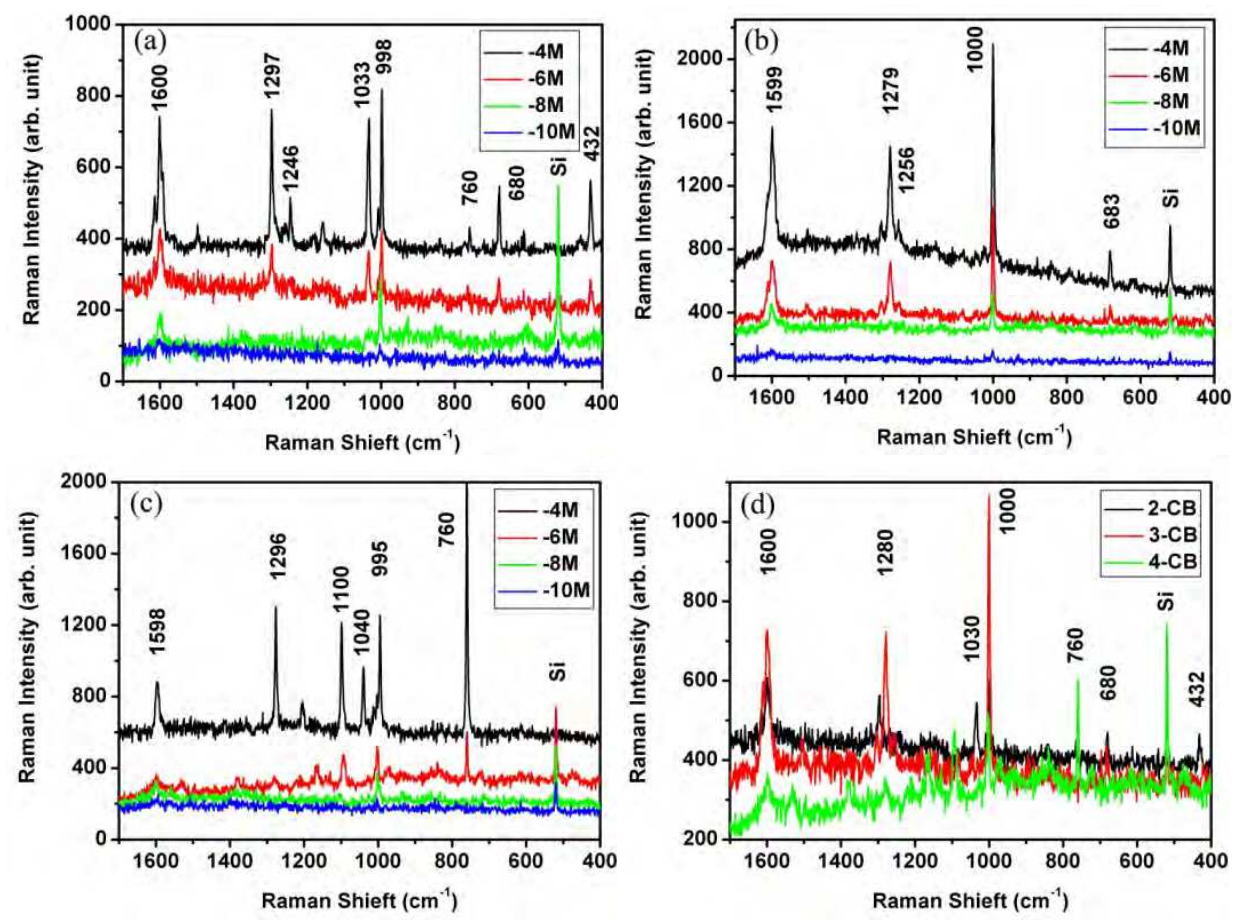

Fig. 12. SERS spectra of (a) 2-chlorobiphenyl; (b) 3-chlorobiphenyl; and (c) 4chlorobiphenyl at concentrations from $10^{-4}$ to $10^{-10} \mathrm{~mol} / \mathrm{L}$ in acetone. (d) Compares the SERS spectra of the three homologues at a concentration of $10^{-6} \mathrm{~mol} / \mathrm{L}$.

In summary, based on the understanding of Raman characteristics of these compounds, one can detect and recognize the homologues of chlorobiphenyls, even at the trace amount, by using the SERS technique with Ag nanorods as substrates.[47]

\section{Detecting trace POPs in real environmental samples}

In sections 4 and 5 we introduced the SERS method to detect and distinguish trace amount PCBs and their isomers and homologues. In those experiments, the PCBs are in acetone solutions, as fundamental study. In this section we introduce some examples in practical trace POPs detection. 


\subsection{Detecting trace PCBs in dry soil samples}

The polluted soil samples were dried and made into small powers which were acquired from the Nanjing Institute of Soil (China). With a combination of the high-resolution gas chromatography and mass spectrometry techniques, sample I proved to contain about 5 $\mu \mathrm{g} / \mathrm{g}$ PCBs and sample II proved to contain about $300 \mu \mathrm{g} / \mathrm{g}$ PCBs. $0.2 \mathrm{~g}$ soil sample I was put into $20 \mathrm{~mL}$ acetone and was agitated uniformly for about 5 minutes. This suspension was precipitated for 30 minutes and the transparent acetone solution in the upper layer was taken as solution sample A. $0.2 \mathrm{~g}$ soil sample I was put into $200 \mathrm{~mL}$ acetone and solution sample B was obtained through the aforementioned process. $0.2 \mathrm{~g}$ soil sample II was put into $20 \mathrm{~mL}$ acetone to obtain solution sample $\mathrm{C}$ and was put into $200 \mathrm{~mL}$ acetone to obtain solution sample D.

The Ag nanorods SERS substrates were put into the solution samples A, B, C and D, respectively. After 30 minutes, the $\mathrm{Ag}$ nanorods substrates were taken out of the solutions and the acetone on the substrates was blown away using a nitrogen flow. The Raman spectra of these substrates dipped into solution samples were measured by a Renishaw Raman 100 spectrometer using a $633 \mathrm{~nm}$ He-Ne laser as the excitation source at room temperature.

Figures 13 (a), (b), (c) and (d) show the measured Raman spectrum of the Ag substrates dipped into sample A, B, C and D, respectively. From Figures 13 (a), (b) and (c), one sees peaks at 1600,1280,1240, 1150, 1030 and $1000 \mathrm{~cm}^{-1}$ clearly, demonstrating the common feature of PCBs. The peaks around $1590 \sim 1600 \mathrm{~cm}^{-1}$ present benzene stretching vibration mode; the peak around $1280 \mathrm{~cm}^{-1}$ presents CC bridge stretching vibration mode; the peak around $1030 \mathrm{~cm}^{-1}$ presents $\mathrm{CH}$ bending in-plane mode; the peak around $1000 \mathrm{~cm}^{-1}$ presents trigonal breathing vibration mode; and peaks around $1240 \sim 1250 \mathrm{~cm}^{-1}$ and $1140 \sim 1200 \mathrm{~cm}^{-1}$ present the vibration peaks induced by $\mathrm{Cl}$ substituent. These characteristic peaks suggest that PCBs in dry soil can be detected by the SERS method by dissolving into acetone. The most widely used PCBs are trichlorobiphenyls and pentachlorobiphenyls, we assumed that the molecular weight of the PCBs in the soil samples is 300, then the concentration of the PCBs acetone solution in solution sample A, $\mathrm{B}, \mathrm{C}$ and $\mathrm{D}$ are about $10^{-5} \mathrm{~mol} / \mathrm{L}, 10^{-5} \mathrm{~mol} / \mathrm{L}, 10^{-6} \mathrm{~mol} / \mathrm{L}, 10^{-7} \mathrm{~mol} / \mathrm{L}$, and $10^{-8} \mathrm{~mol} / \mathrm{L}$, respectively. Thus, with silver nanorod substrates, 5ug/g PCBs in dry soil samples can be detected by the SERS method.

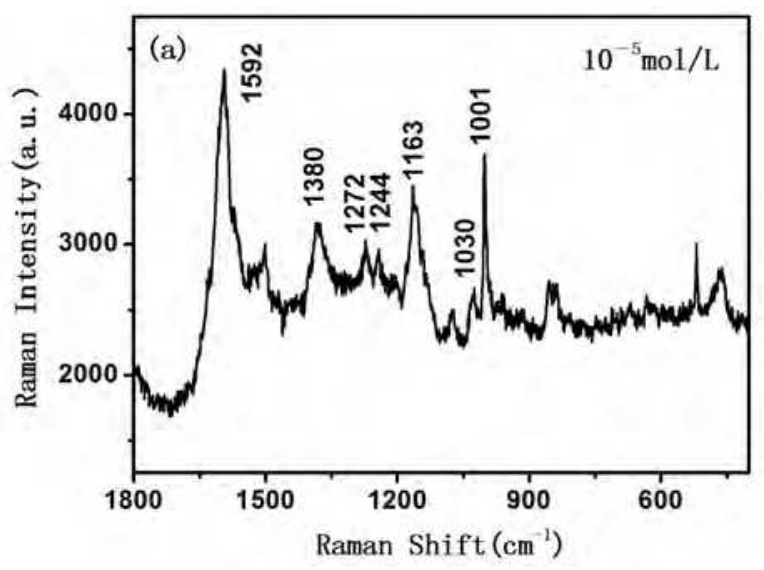



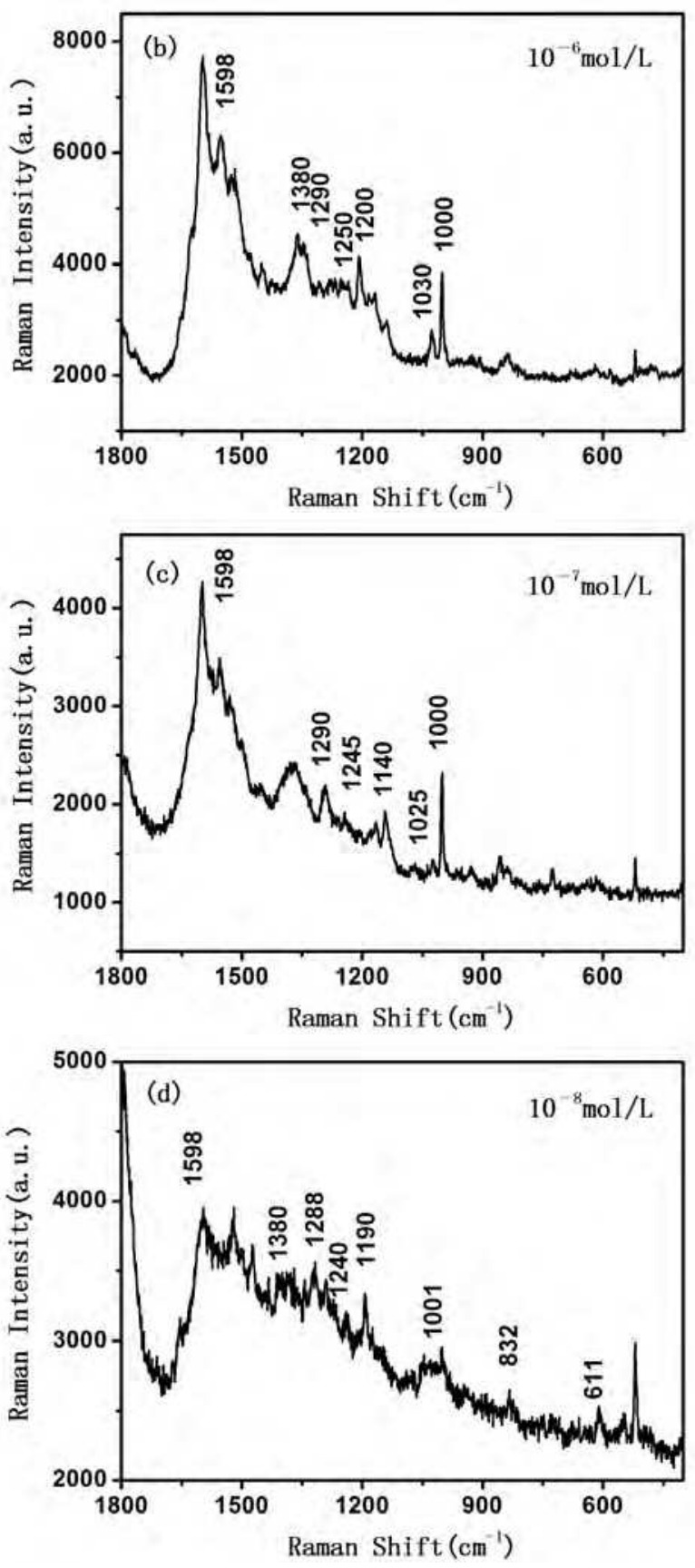

Fig. 13. SERS spectra of PCBs in dry soil samples after being treated by acetone: (a) $\sim 10^{-5}$ $\mathrm{mol} / \mathrm{L}$; (b) 10-6 mol/L; (c) $\sim 10^{-7} \mathrm{~mol} / \mathrm{L}$; (d) $\sim 10^{-8} \mathrm{~mol} / \mathrm{L}$. 


\subsection{Detecting PCBs in white spirit}

PCBs in white spirit can also be detected by the SERS method with silver nanorod substrates. The concentration of PCBs in white spirit is about $10^{-4} \mathrm{~mol} / \mathrm{L}$. We put a drop of PCBs "polluted" white spirit on the silver nanorod substrates and made the white spirit volatilized away. Then, we found PCBs Raman signal with the SERS method described before. Figures 14 (a) and (b) show the SERS spectra of pure white spirit and white spirit with $10^{-4} \mathrm{~mol} / \mathrm{L}$ PCBs, respectively. One can recognize characteristic Raman peaks of PCBs around 1590, 1290, 1240, 1030 and $1000 \mathrm{~cm}^{-1}$ in Figure 14 (b).
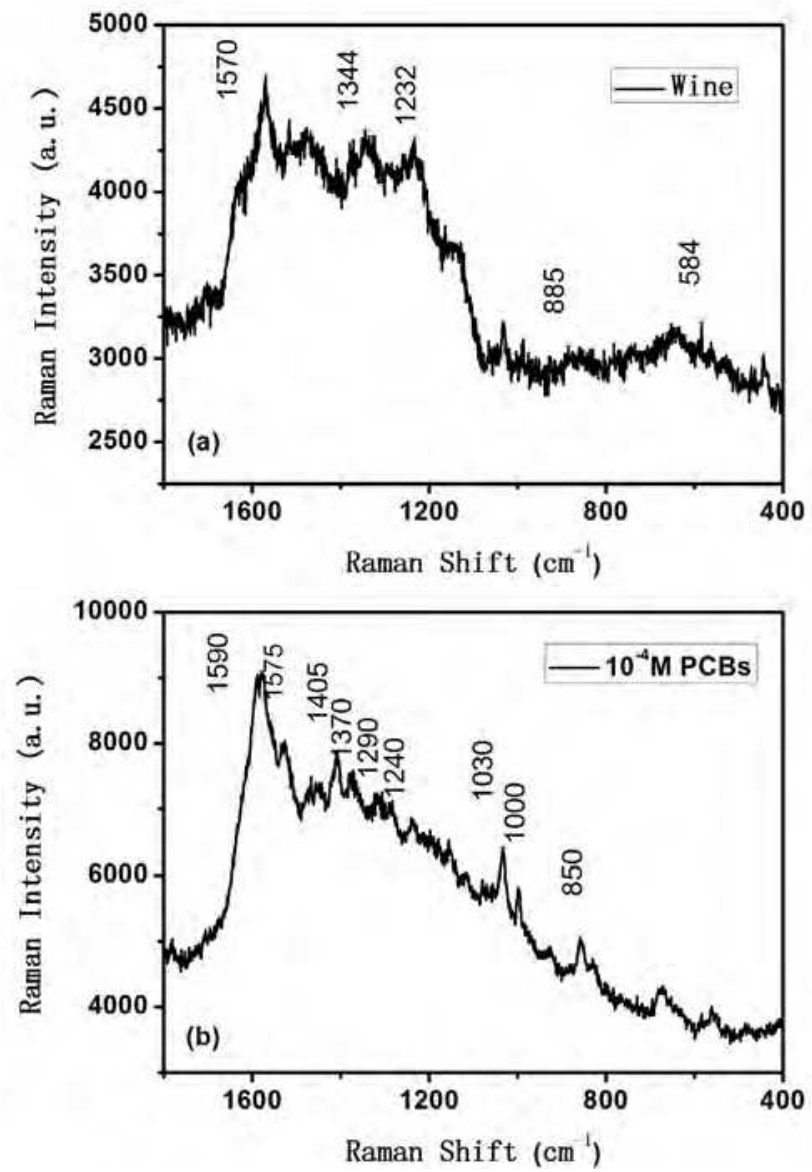

Fig. 14. SERS spectra of white spirit without and with PCBs.

\subsection{Detecting melamine in milk}

In the year 2009, milk produced by Sanlu Co. (China) was found to contain amounts of Melamine in much higher concentrations than usual. Milk with Melamine seems to contain more protein when detecting nitrogen concentration, but it is poisonous to 
children. With the SERS method with silver nanorods as substrates, we detected Melamine in milk. Figures 15 (a) and (b) show the SERS spectra of pure Melamine and milk with Melamine.
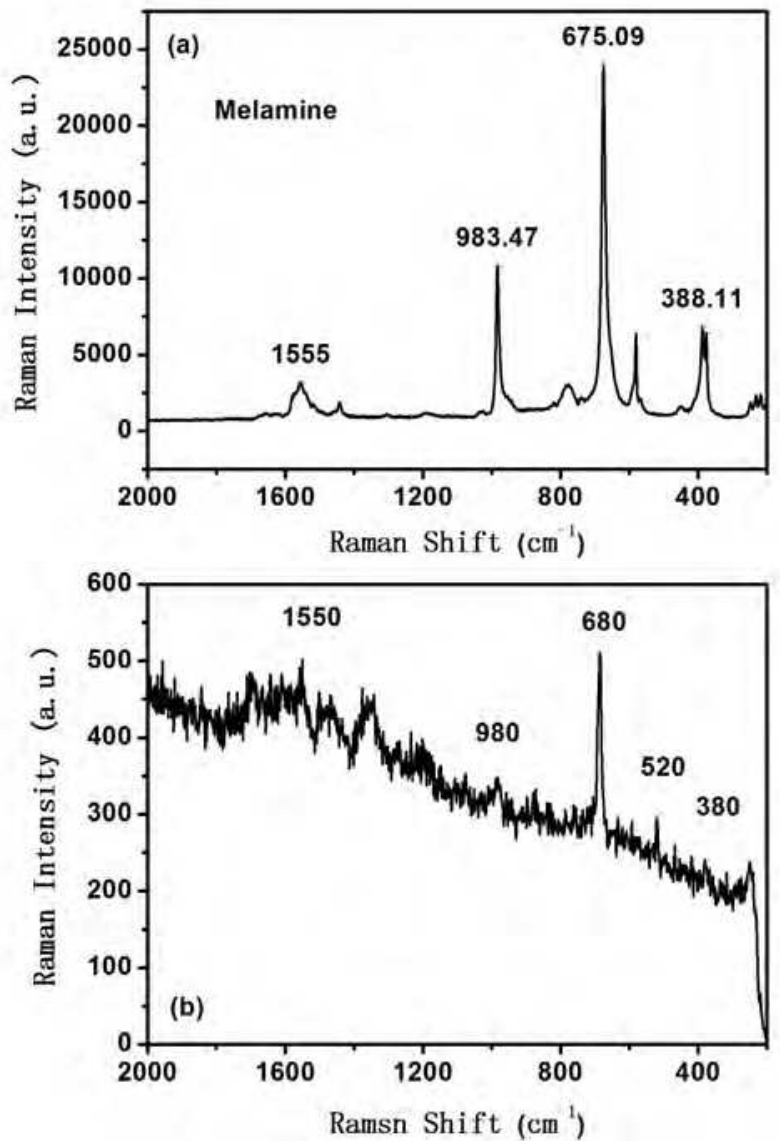

Fig. 15. SERS spectra of Melamine and trace Melamine in milk.

\section{Summary}

Although persistent organic pollutants such as PCBs are difficult to detect at trace amount, they can be detected and recognized rapidly via the SERS technique. Ag nanostructured SERS substrates prepared by the glancing angle deposition method are excellent at detection and their sensitivity can be further improved by tuning the thin underlayer films and Ag nanorod structures. With well designed and prepared Ag nanostructured SERS substrates, pentachlorinated biphenyl molecules are detected and isomers of chlorobiphenyl molecules are recognized at trace level using the SERS method. These series of studies provide a potential method for trace pollutant detection via nano technology. 


\section{References}

[1] Ross G. The public health implications of polychlorinated biphenyls (pcbs) in the environment. Ecotoxicology and Environmental Safety, 2004, 59(3): 275 291.

[2] Ohtsubo Y, Kudo T, Tsuda M, et al. Strategies for bioremediation of polychlorinated biphenyls. Applied Microbiology and Biotechnology, 2004, 65(3): 250 258.

[3] Cicchetti D V, Kaufman A S, Sparrow S S. The relationship between prenatal and postnatal exposure to polychlorinated biphenyls (pcbs) and cognitive, neuropsychological, and behavioral deficits: a critical appraisal. Psychology in the Schools, 2004, 41(6): 589 624.

[4] Hong J E, Pyo H, Park S J, et al. Determination of hydroxy-pcbs in urine by gas chromatography/mass spectrometry with solid-phase extraction and derivatization. Analytica Chimica Acta, 2005, 531(2): 249 256.

[5] Namiesnik J, Zygmunt B. Selected concentration techniques for gas chromatographic analysis of environmental samples. Chromatographia, 2002, 56Suppl. S: S9 S18.

[6] Pitarch E, Serrano R, Lopez F J, et al. Rapid multiresidue determination of organochlorine and organophosphorus compounds in human serum by solidphase extraction and gas chromatography coupled to tandem mass spectrometry. Analytical and Bioanalytical Chemistry, 2003, 376(2): 189 197.

[7] Barra R, Cisternas M, Suarez C, et al. Pcbs and hchs in a salt-marsh sediment record from south-central Chile: use of tsunami signatures and cs-137 fallout as temporal markers. Chemosphere, 2004, 55(7): 965 972.

[8] Moskovits M. Surface-enhanced spectroscopy. Reviews of Modern Physics, 1985, 57(3): $783 \sim 826$.

[9] Zhou Q, Li Z C, Yang Y, et al. Arrays of aligned, single crystalline silver nanorods for trace amount detection. Journal of Physics D-Applied Physics, 2008, 41(15200715).

[10] Kudelski A. Analytical applications of raman spectroscopy. Talanta, 2008, 76(1): $1 \sim 8$.

[11] Zhang X Y, Zhao J, Whitney A V, et al. Ultrastable substrates for surface-enhanced raman spectroscopy: al2o3 overlayers fabricated by atomic layer deposition yield improved anthrax biomarker detection. Journal of the American Chemical Society, 2006, 128(JA063876031): 10304 10309.

[12] Tan R Z, Agarwal A, Balasubramanian N, et al. 3d arrays of sers substrate for ultrasensitive molecular detection. Sensors and Actuators a-Physical, 2007, 139(12Sp. Iss. SI): 36 41.

[13] Isola N R, Stokes D L, Vo-Dinh T. Surface enhanced raman gene probe for hiv detection. Analytical Chemistry, 1998, 70(7): 1352 1356.

[14] Vodinh T, Houck K, Stokes D L. Surface-enhanced raman gene probes. Analytical Chemistry, 1994, 66(20): 3379 3383.

[15] Tripp R A, Dluhy R A, Zhao Y P. Novel nanostructures for sers biosensing. Nano Today, 2008, 3(3-4): 31 37.

[16] Chaney S B, Shanmukh S, Dluhy R A, et al. Aligned silver nanorod arrays produce high sensitivity surface-enhanced raman spectroscopy substrates. Applied Physics Letters, 2005, 87(0319083). 
[17] Zhang Z Y, Zhao Y P. Tuning the optical absorption properties of ag nanorods by their topologic shapes: a discrete dipole approximation calculation. Applied Physics Letters, 2006, 89(0231102).

[18] Malac M, Egerton R F, Brett M J, et al. Fabrication of submicrometer regular arrays of pillars and helices. Journal of Vacuum Science \& Technology B, 1999, 17(6): 2671 2674.

[19] Dick B, Brett M J, Smy T. Investigation of substrate rotation at glancing-incidence on thin-film morphology. Journal of Vacuum Science \& Technology B, 2003, 21(6): 2569 2575.

[20] Dick B, Brett M J, Smy T J, et al. Periodic magnetic microstructures by glancing angle deposition. Journal of Vacuum Science \& Technology A-Vacuum Surface and Films, 2000, 18(4Part 2): 1838 1844.

[21] Alouach H, Fujiwara H, Mankey G J. Magnetocrystalline anisotropy in glancing angle deposited permalloy nanowire arrays. Journal of Vacuum Science $\mathcal{E}$ Technology A, 2005, 23(4): 1046 1050.

[22] Singh J P, Tang F, Karabacak T, et al. Enhanced cold field emission from 100 oriented beta-w nanoemitters. Journal of Vacuum Science \& Technology B, 2004, 22(3): 1048 1051.

[23] Hawkeye M M, Brett M J. Glancing angle deposition: fabrication, properties, and applications of micro- and nanostructured thin films. Journal of Vacuum Science $\mathcal{E}$ Technology A, 2007, 25(5): 1317 1335.

[24] Leverette C L, Shubert V A, Wade T L, et al. Development of a novel dual-layer thick ag substrate for surface-enhanced raman scattering (sers) of self-assembled monolayers. Journal of Physical Chemistry B, 2002, 106(34): 8747 8755.

[25] Li H G, Cullum B M. Dual layer and multilayer enhancements from silver film over nanostructured surface-enhanced raman substrates. Applied Spectroscopy, 2005, 59(4): 410 417.

[26] Li H G, Baum C E, Sun J, et al. Multilayer enhanced gold film over nanostructure surface-enhanced raman substrates. Applied Spectroscopy, 2006, 60(12): 1377 1385.

[27] Yang Y A, Bittner A M, Kern K. A new sers-active sandwich structure. Journal of Solid State Electrochemistry, 2007, 11(2): 150 154.

[28] Mulvaney S P, He L, Natan M J, et al. Three-layer substrates for surface-enhanced raman scattering: preparation and preliminary evaluation. Journal of Raman Spectroscopy, 2003, 34(2): 163 171.

[29] Driskell J D, Shanmukh S, Liu Y, et al. The use of aligned silver nanorod arrays prepared by oblique angle deposition as surface enhanced raman scattering substrates. Journal of Physical Chemistry C, 2008, 112(4): 895 901.

[30] Driskell J D, Lipert R J, Porter M D. Labeled gold nanoparticles immobilized at smooth metallic substrates: systematic investigation of surface plasmon resonance and surface-enhanced raman scattering. Journal of Physical Chemistry B, 2006, 110(35): 17444 17451.

[31] Addison C J, Brolo A G. Nanoparticle-containing structures as a substrate for surface-enhanced raman scattering. Langmuir, 2006, 22(21): 8696 8702. 
[32] Misra A K, Sharma S K, Kamemoto L, et al. Novel micro-cavity substrates for improving the raman signal from submicrometer size materials. Applied Spectroscopy, 2009, 63(3): 373 377.

[33] Shoute L, Bergren A J, Mahmoud A M, et al. Optical interference effects in the design of substrates for surface-enhanced raman spectroscopy. Applied Spectroscopy, 2009, 63(2): 133 140.

[34] Liu Y J, Zhao Y P. Simple model for surface-enhanced raman scattering from tilted silver nanorod array substrates. Physical Review B, 2008, 78(0754367).

[35] Mitsas C L, Siapkas D I. Generalized matrix-method for analysis of coherent and incoherent reflectance and transmittance of multilayer structures with rough surfaces, interfaces, and finite substrates. Applied Optics, 1995, 34(10): 1678 1683.

[36] Fu J X, Park B, Zhao Y P. Nanorod-mediated surface plasmon resonance sensor based on effective medium theory. Applied Optics, 2009, 48(23): 4637 4649.

[37] Abell J L, Driskell J D, Dluhy R A, et al. Fabrication and characterization of a multiwell array sers chip with biological applications. Biosensors $\mathcal{E}$ Bioelectronics, 2009, 24(12): 3663 3670.

[38] Yang W H, Hulteen J, Schatz G C, et al. A surface-enhanced hyper-raman and surface-enhanced raman scattering study of trans-1,2-bis(4-pyridyl)ethylene adsorbed onto silver film over nanosphere electrodes. Vibrational assignments: experiment and theory. Journal of Chemical Physics, 1996, 104(11): 4313 4323.

[39] Zhou Q, Liu Y J, He Y P, et al. The effect of underlayer thin films on the surfaceenhanced raman scattering response of ag nanorod substrates. Applied Physics Letters, 2010, 97(12190212).

[40] Michaels A M, Jiang J, Brus L. Ag nanocrystal junctions as the site for surfaceenhanced raman scattering of single rhodamine $6 \mathrm{~g}$ molecules. Journal of Physical Chemistry B, 2000, 104(50): 11965 11971.

[41] Mcfarland A D, Young M A, Dieringer J A, et al. Wavelength-scanned surfaceenhanced raman excitation spectroscopy. Journal of Physical Chemistry B, 2005, 109(22): $11279 \sim 11285$.

[42] Qin L D, Zou S L, Xue C, et al. Designing, fabricating, and imaging raman hot spots. Proceedings of the National Academy of Sciences of the United States of America, 2006, 103(36): 13300 13303.

[43] Liu Y J, Zhang Z Y, Zhao Q, et al. Surface enhanced raman scattering from an ag nanorod array substrate: the site dependent enhancement and layer absorbance effect. Journal of Physical Chemistry C, 2009, 113(22): 9664 9669.

[44] Gansel J K, Thiel M, Rill M S, et al. Gold helix photonic metamaterial as broadband circular polarizer. Science, 2009, 325(5947): 1513 1515.

[45] Zhou Q, Yang Y, Ni J, et al. Rapid detection of 2, 3, 3', 4, 4'-pentachlorinated biphenyls by silver nanorods-enhanced raman spectroscopy. Physica E-LowDimensional Systems \& Nanostructures, 2010, 42(5): 1717 1720.

[46] Fleming G D, Golsio I, Aracena A, et al. Theoretical surface-enhanced raman spectra study of substituted benzenes i. Density functional theoretical sers modelling of benzene and benzonitrile. Spectrochimica Acta Part a-Molecular and Biomolecular Spectroscopy, 2008, 71(3): 1049 1055. 
[47] Zhou Q, Yang Y, Ni J E, et al. Rapid recognition of isomers of monochlorobiphenyls at trace levels by surface-enhanced raman scattering using ag nanorods as a substrate. Nano Research, 2010, 3(6): 423 428. 


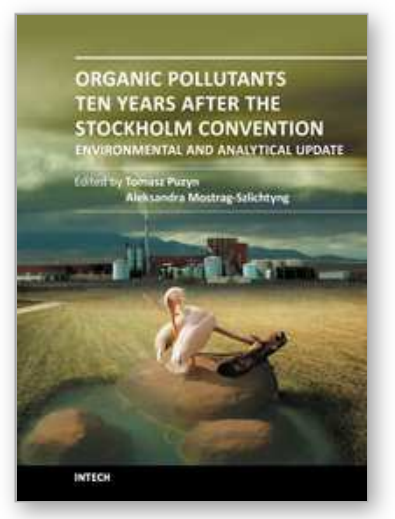

\section{Organic Pollutants Ten Years After the Stockholm Convention - Environmental and Analytical Update}

Edited by Dr. Tomasz Puzyn

ISBN 978-953-307-917-2

Hard cover, 472 pages

Publisher InTech

Published online 24, February, 2012

Published in print edition February, 2012

Ten years after coming into force of the Stockholm Convention on Persistent Organic Pollutants (POPs), a wide range of organic chemicals (industrial formulations, plant protection products, pharmaceuticals and personal care products, etc.) still poses the highest priority environmental hazard. The broadening of knowledge of organic pollutants (OPs) environmental fate and effects, as well as the decontamination techniques, is accompanied by an increase in significance of certain pollution sources (e.g. sewage sludge and dredged sediments application, textile industry), associated with a potential generation of new dangers for humans and natural ecosystems. The present book addresses these aspects, especially in the light of Organic Pollutants risk assessment as well as the practical application of novel analytical methods and techniques for removing OPs from the environment. Providing analytical and environmental update, this contribution can be particularly valuable for engineers and environmental scientists.

\section{How to reference}

In order to correctly reference this scholarly work, feel free to copy and paste the following:

Zhengjun Zhang, Qin Zhou and Xian Zhang (2012). Rapid Detection and Recognition of Organic Pollutants at Trace Levels by Surface-Enhanced Raman Scattering, Organic Pollutants Ten Years After the Stockholm Convention - Environmental and Analytical Update, Dr. Tomasz Puzyn (Ed.), ISBN: 978-953-307-917-2, InTech, Available from: http://www.intechopen.com/books/organic-pollutants-ten-years-after-the-stockholmconvention-environmental-and-analytical-update/rapid-detection-and-recognition-of-organic-pollutants-attrace-levels-by-surface-enhanced-raman-scat

\section{INTECH}

open science | open minds

\author{
InTech Europe \\ University Campus STeP Ri \\ Slavka Krautzeka 83/A \\ 51000 Rijeka, Croatia \\ Phone: +385 (51) 770447 \\ Fax: +385 (51) 686166 \\ www.intechopen.com
}

\author{
InTech China \\ Unit 405, Office Block, Hotel Equatorial Shanghai \\ No.65, Yan An Road (West), Shanghai, 200040, China \\ 中国上海市延安西路65号上海国际贵都大饭店办公楼405单元 \\ Phone: $+86-21-62489820$ \\ Fax: $+86-21-62489821$
}


(C) 2012 The Author(s). Licensee IntechOpen. This is an open access article distributed under the terms of the Creative Commons Attribution 3.0 License, which permits unrestricted use, distribution, and reproduction in any medium, provided the original work is properly cited. 